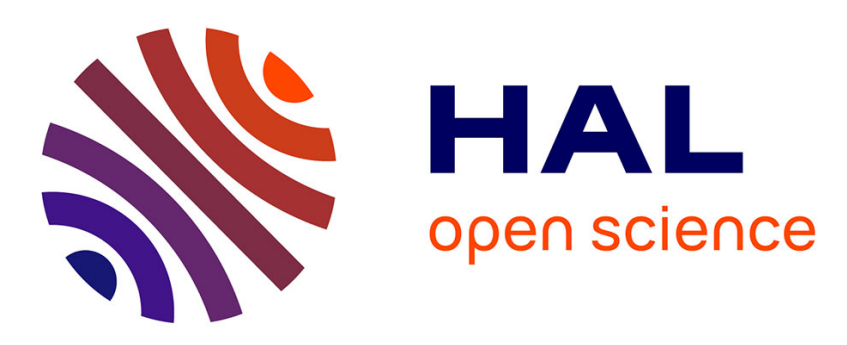

\title{
Review on Liquid Piston technology for compressed air energy storage
}

El Mehdi Gouda, Yilin Fan, Mustapha Benaouicha, Thibault Neu, Lingai Luo

\section{To cite this version:}

El Mehdi Gouda, Yilin Fan, Mustapha Benaouicha, Thibault Neu, Lingai Luo. Review on Liquid Piston technology for compressed air energy storage. Journal of Energy Storage, 2021, 43, pp.103111. 10.1016/j.est.2021.103111 . hal-03344422

\section{HAL Id: hal-03344422 \\ https://hal.science/hal-03344422}

Submitted on 15 Sep 2021

HAL is a multi-disciplinary open access archive for the deposit and dissemination of scientific research documents, whether they are published or not. The documents may come from teaching and research institutions in France or abroad, or from public or private research centers.
L'archive ouverte pluridisciplinaire HAL, est destinée au dépôt et à la diffusion de documents scientifiques de niveau recherche, publiés ou non, émanant des établissements d'enseignement et de recherche français ou étrangers, des laboratoires publics ou privés. 


\title{
Review on Liquid Piston technology for compressed air energy storage
}

\author{
El Mehdi GOUDA ${ }^{\mathrm{a}, \mathrm{b}}$, Yilin FAN ${ }^{\mathrm{b}}$, Mustapha BENAOUICHA ${ }^{\mathrm{a}, *}$, Thibault \\ $\mathrm{NEU}^{\mathrm{a}}$, Lingai LUO ${ }^{\mathrm{b}, *}$ \\ ${ }^{a}$ Segula Technologies. Naval and Energy Engineering Research and Innovation Unit. 9 \\ avenue Edouard Belin, 92500 Rueil-Malmaison, France \\ ${ }^{b}$ Université de Nantes, CNRS, Laboratoire de Thermique et Énergie de Nantes, LTeN, \\ UMR 6607, F-44000 Nantes, France
}

\begin{abstract}
Compressed air energy storage systems (CAES) have demonstrated the potential for the energy storage of power plants. One of the key factors to improve the efficiency of CAES is the efficient thermal management to achieve near isothermal air compression/expansion processes. This paper presents a review on the Liquid Piston (LP) technology for CAES as a timely documentary on this topic with rapidly growing interests. Various aspects are discussed including the state-of-the-art on LP projects all over the world and the trend of development, the coupled fluid flow and heat transfer during the compression/expansion operations, and different actions proposed and implemented to enhance the heat transfer inside the piston column.

It has been found that LP is a promising concept for isothermal CAES. However, the complex and transient fluid flow and heat transfer behaviors inside the LP are difficult to characterize and master. To enhance the heat transfer and increase the efficiency of the compression/expansion processes many approaches have been tested including liquid spray, wire mesh, porous media, optimal trajectory, hollow spheres and optimal geometry of the piston column. Numerous Nusselt number's empirical correlations have also been proposed to estimate the
\end{abstract}

DOI: https://doi.org/10.1016/j.est.2021.103111

* Corresponding author

Email addresses: Mustapha.benaouicha@segula.fr (Mustapha BENAOUICHA), lingai.luo@univ-nantes.fr (Lingai LUO)

Preprint submitted to Journal of Energy Storage

September 2, 2021 
heat transfer in different types of LP, as reviewed and summarized in this paper.

Keywords: Liquid Piston (LP), Compressed Air Energy Storage (CAES),

Compression and expansion, Flow pattern, Heat transfer enhancement,

Thermal management

\section{Nomenclature}

\section{Abbreviations}

3 A-CAES Adiabatic Compressed Air Energy Storage

4 ABS Acrylonitrile Butadiene Styrene

5 CAES Compressed Air Energy Storage

6 CFD Computational Fluid Dynamics

7 CR Compression Ratio

8 D-CAES Diabatic Compressed Air Energy Storage

9 ESS Energy Storage System

10 HDPE High-Density Polyethylene

11 HTE Heat Transfer Enhancement

12 I-CAES Isothermal Compressed Air Energy Storage

${ }_{13}$ LP Liquid Piston

14 MDD Mean Droplet Diameter

$15 \quad$ ML Mass Loading

${ }_{16}$ Mtoe Million tonnes of oil equivalent

${ }_{17}$ PP Polypropylene

${ }_{18}$ PPI Pores per inch 
1 PSH Pumped-Storage Hydropower

2 RTE Round Trip Efficiency

3 SMES Superconducting Magnetic Energy Storage

${ }_{4}$ VOF Volumn of fluid

\section{Greek Symbols}

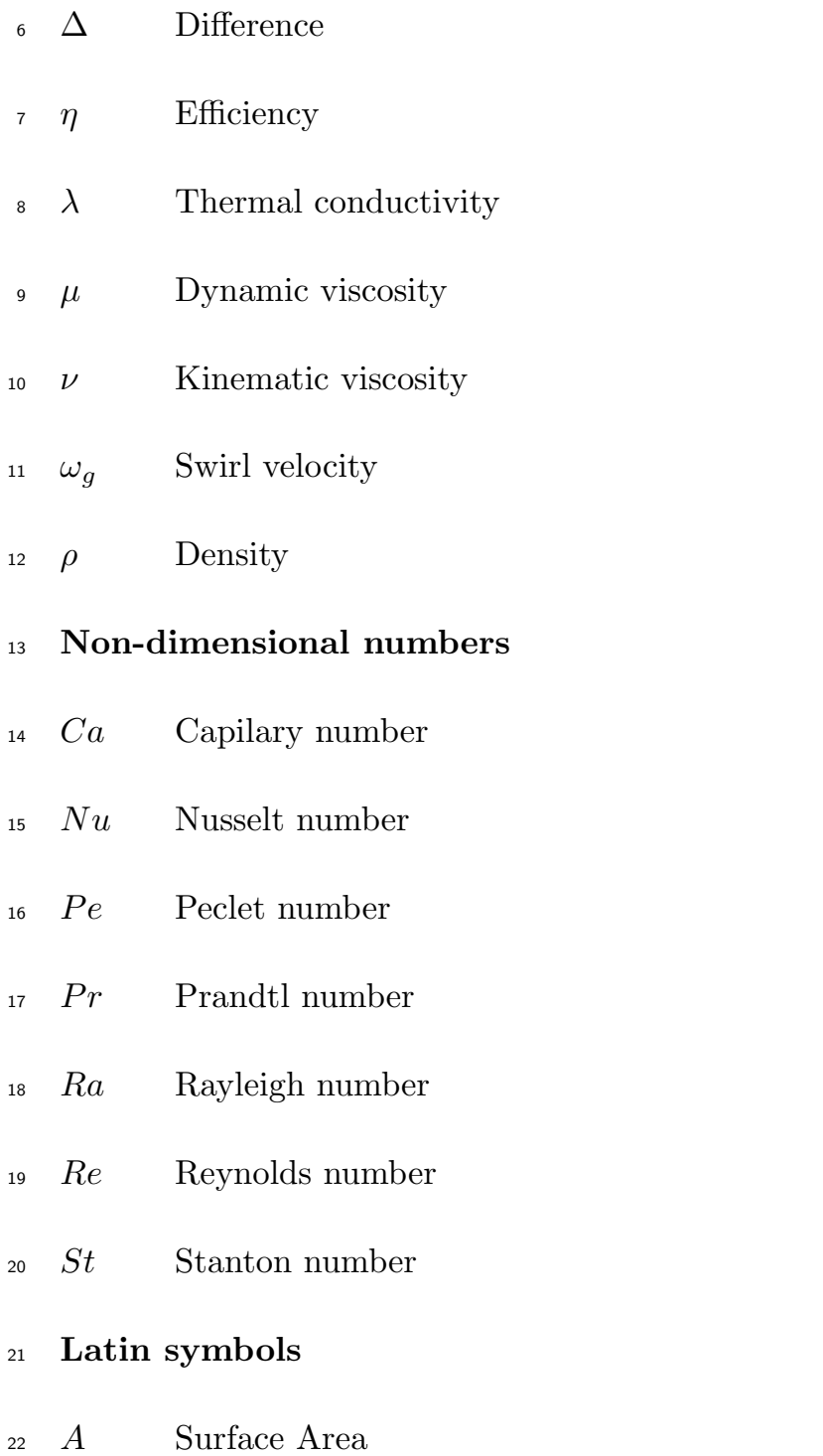




\begin{tabular}{|c|c|}
\hline${ }_{1} \quad c_{p}$ & Constant pressure heat capacity \\
\hline $2 \quad c_{v}$ & Constant volume heat capacity \\
\hline${ }^{3} \quad D$ & Diameter \\
\hline${ }_{4} E$ & Energy \\
\hline${ }^{5} \quad f_{r}$ & Friction factor \\
\hline $6 \quad g$ & Gravitational acceleration \\
\hline $7 \quad H$ & Global heat transfer coefficient \\
\hline$h$ & Heat transfer coefficient \\
\hline$L$ & Length \\
\hline$m$ & Mass \\
\hline$n$ & Polytropic index \\
\hline$P$ & Pressure \\
\hline$Q$ & Heat flow rate \\
\hline$R$ & Radius \\
\hline $5 T$ & Temperature \\
\hline $6 t$ & Time \\
\hline 7 th & Thickness \\
\hline$U$ & Velocity \\
\hline$V$ & Volume \\
\hline$W$ & Work \\
\hline${ }_{1} \quad X$ & Position \\
\hline
\end{tabular}




\begin{tabular}{|c|c|c|}
\hline 1 & 0 & Initial at $t=0 \mathrm{~s}$ \\
\hline 2 & air & Air \\
\hline 3 & $a m b$ & Ambient \\
\hline 4 & ave & Average \\
\hline 5 & $c$ & Compression \\
\hline 6 & $e$ & Expansion \\
\hline 7 & $f$ & Final at $t=t_{f}$ \\
\hline 8 & fo & Foam \\
\hline 9 & $G$ & Gas \\
\hline 10 & $i$ & Inner \\
\hline 11 & iso & Isothermal \\
\hline 12 & $L$ & Liquid \\
\hline 13 & lam & Laminar \\
\hline 14 & $l c$ & Characteristic Length \\
\hline 15 & $o$ & Outer \\
\hline 16 & ref & Reference \\
\hline 17 & $\operatorname{tr}$ & Transition \\
\hline 18 & turb & Turbulent \\
\hline 19 & $W$ & Wall \\
\hline 20 & water & Water \\
\hline
\end{tabular}




\section{Introduction}

The energy consumption worldwide has increased by $21 \%$ from year 2009 to 2019 and is expected to grow with more than $50 \%$ by 2050 1]. To meet this demand, the world energy production reached 14421 Mtoe (million tonnes of oil equivalent) in 2018 , with more than $81 \%$ driven by fossil fuels (natural gas, coal and oil) 2. In the meantime, awareness has been raised on the concomitant environmental impacts due to the greenhouse gas emission, evidenced by the signing of the Paris Agreement [3] in 2016 aiming at substantially reducing the global warming and the risks of climate change. In this context, renewable energies, with their increasing contribution year by year to the global energy market, are expected to play a major role to achieve the COP21 objectives for a more sustainable and decarbonized future [3].

Most renewable energy sources (e.g., solar, wind, tidal) show the intermittent character, bringing more difficulties for their exploitation at large scale. In this regard, the Energy Storage Systems (ESSs) have become an essential element for the power generation plants driven by renewable sources so as to augment their reliability and dispatchability [4. Moreover, the integration of ESSs brings additional economic benefits by storing the excess power produced at times of low demand or low generation cost to be used during the peak periods with a higher price, accelerating thereby the pathway to a flexible, low-cost and electrified future [5, 4. Different types of ESSs have been developed and utilized in the past decades, classified as follows based on their storage mechanisms.

- Electrical energy storage: electrostatic energy storage including capacitors and super-capacitors, magnetic/current energy storage including Superconducting Magnetic Energy Storage (SMES), etc. [5;

- Thermal energy storage: sensible, latent and thermochemical heat storage [6, 7, 8, 9];

- Mechanical energy storage: kinetic energy storage (flywheels), potential energy storage (Pumped-Storage Hydropower (PSH) and Compressed Air 
- Chemical energy storage: hydrogen, methane, etc. [5];

4

- Electrochemical energy storage: batteries (lead-acid, lithium-ion, nickelcadmium, etc.) and fuel cells [1].

Among all these energy storage technologies, the PSH and CAES have been proven to be the most adapted one to store electricity in large scale [12]. PSH is a mature technology featured by its large power capacity (100-3000 MW), long storage period (1-24 h) and high Round Trip Efficiency (RTE) (71\% to 85\%) 13. Therefore, it has dominated the energy storage market accounting for $95 \%$ of the global capacity (over $100 \mathrm{GW}$ ) 14. Its main drawback lies in the rareness of available sites for two large reservoirs and one or two dams, a long construction time required (typically about 10 years) and high investment costs (typically hundreds to thousands of million US dollars). Moreover, removing trees and vegetation from the vast land prior to the flooding of reservoirs also appends additional environmental impacts. For these reasons, the planning of new PSH sites has been limited in the past years 13 despite that the overall new power installation is still dominating [15. In the meantime, the CAES technology has experienced a rapid growth in recent years, demonstrating the potential to become the next major ESS for power plants 12 .

\subsection{Compressed Air Energy Storage}

Storing electrical energy using a compressed air system can be dated back to the early $20^{\text {th }}$ century 13 , in a way that it decoupled a conventional gas turbine cycle into separated compression and expansion processes [16. The energy was stored in the form of elastic potential energy of compressed air and could be restituted by expanding it through turbines to reproduce the electricity. The waste heat of the exhaust gas can be captured through a recuperator before being released to the atmosphere. In modern CAES systems, the compressed air can be stored either in man-made containers at the ground level or underground 
(salt caverns, hard rock caverns, saline aquifers) [17, 18, 19]. Offshore and underwater storage systems have also been tested and are under rapid development 12. Capital costs for CAES facilities depend on the storage conditions, ranging typically between $400 \$$ and $800 \$$ per $\mathrm{kW}$ [20]. Above-ground systems usually request higher investments than underground ones [13, 15].

Since the gas compression and expansion processes involve a large amount of heat, the efficiency and storage capacity of the CAES systems depend strongly on the heat transfer behaviors. Different variants of CAES exist, distinguishing themselves by the manner of thermal management.

- Diabatic-CAES (D-CAES): this technology pressurises and heats air by combusting a fuel (usually natural gas) and expands it though turbo turbines to generate electricity. It is the basic but the only industrialized version of the CAES at large scale [21, 5, 12. Nevertheless, gas emissions are inevitable due to the fuel combustion required to drive the gas compressor.

- Adiabatic-CAES (A-CAES): the main improvement for this second generation of CAES is to retain the heat of the compressed air rather than wasting it, to be used then in the expansion process. As a result, it renders higher efficiency than that of D-CAES systems.

- Isothermal-CAES (I-CAES): this emerging technological variant tries to prevent the temperature increase in the compressors (during charging) and the temperature drop (during discharging) in the expansion devices, permitting isothermal cyclic operations. The main advantage of I-CAES is that fossil-based backup is not needed to start the expansion, implying higher efficiencies and more environmental friendliness [12, 5].

\subsection{Liquid Piston technology}

It is by far very difficult to achieve isothermal compression and expansion using conventional devices. The heat transfer of the system has to be very efficiently mastered to dissipate (almost) all the heat generated in the compression 
1 process, and vice versa, to provide necessary heat for the expansion. Therefore, all I-CAES concepts known so far are based on piston machinery capable of performing a comparably slow compression or expansion, leaving enough time for heat exchange to approach a near-isothermal condition.

In this context, the interest over Liquid Piston (LP) for CAES usage has been rapidly growing in recent years. In the LP compressor, a column of liquid (usually water) is pumped in to compress a fixed amount of gas (usually air). The main advantages of LPs compared to solid piston machinery is that the gas leakage can be avoided and the dissipations due to friction be largely reduced, leading to a higher efficiency. Many CAES projects with LP concept have been developed or are under construction, as listed in Table 1. For example, the GLIDES project (at ground level) by Oak Ridge National Laboratory using liquid spray injection to enhance heat transfer reported a $66 \%$ RTE for their LP prototype 22. More recently, other modifications to the system have been introduced and several tests have been carried out by replacing the noncondensable air with a condensable gas $\left(\mathrm{CO}_{2}\right.$, synthetic refrigerants, hydrocarbon refrigerants, etc.) [23]. Near isothermal and near isobaric charging/discharging processes could be achieved.

Moreover, the LP concept suits especially the underwater/sub-sea CAES systems in that the heat exchange can be largely enhanced due to the cold water environment with high heat capacity. Park et al. 24] have developed a simplified model (steady-state operation; ideal gas) and a proof-of-concept experiment for a compression process by LP. Their study was later completed by Patil \& Ro [25, 26]. It has been estimated that the RTE of their 2 MWh stored energy CAES system could reach $51 \%$ with a compressor/expander efficiency of $79 \%$, and up to $73 \%$ with a higher compressor/expander efficiency of $95 \%$. More recently, the REMORA project [27, 28, 29] showed that near-isothermal condition could be achieved with a LP.-based compression/expansion cycle due to the increased air storage pressure and the reduced heat loss. A 95\% compression efficiency could so achieved by the LP, leading to a 70\% RTE for the CAES system [27, 29].

${ }_{31}$ Table 1 lists different CAES projects, where it could be seen that D-CAES is 
1 the only implemented technology already in service. I-CAES, although still 2 underdevelopment, could be promising because it can theoretically offer higher 3 RTE 


\begin{tabular}{|c|c|c|c|c|c|c|c|c|}
\hline 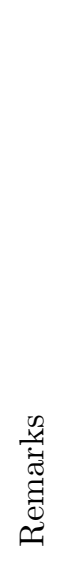 & 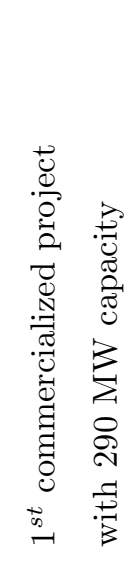 & 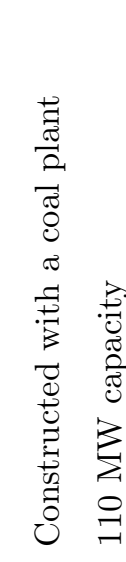 & 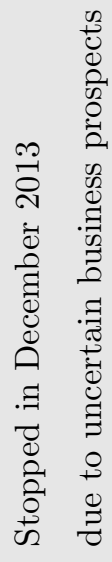 & 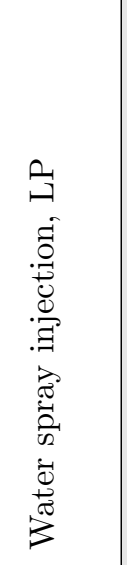 & 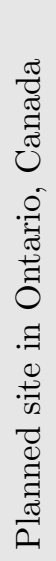 & 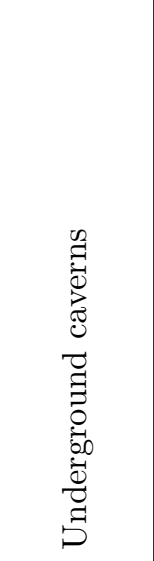 & 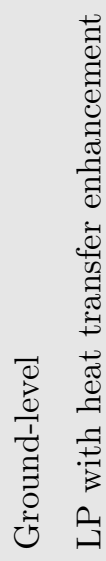 & 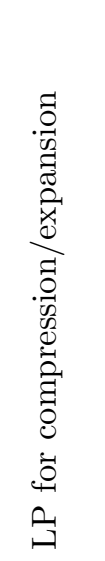 \\
\hline 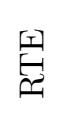 & 웜 & $\begin{array}{l}\frac{\Delta 0}{20} \\
\frac{1}{10}\end{array}$ & 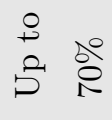 & $\begin{array}{l}\text { de } \\
\text { R }\end{array}$ & $\begin{array}{l}\text { de } \\
\stackrel{R}{1}\end{array}$ & 1 & 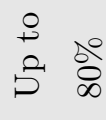 & 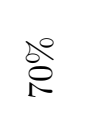 \\
\hline 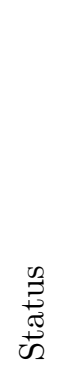 & 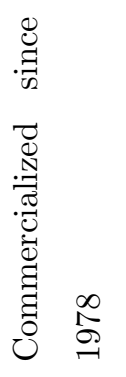 & 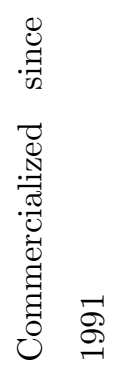 & 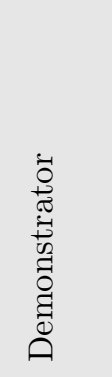 & 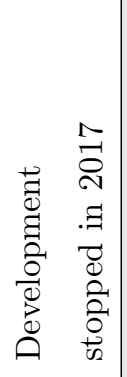 & 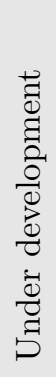 & 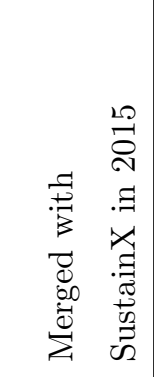 & 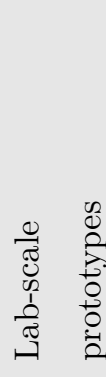 & 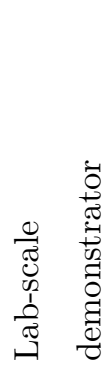 \\
\hline 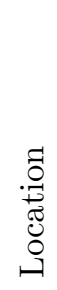 & 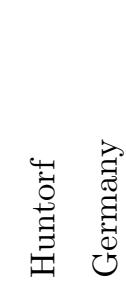 & 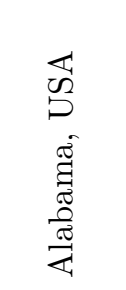 & 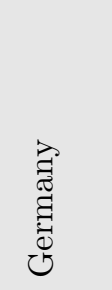 & 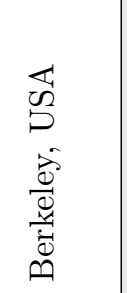 & 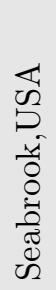 & $\begin{array}{l}\text { 吕 } \\
\text { D }\end{array}$ & 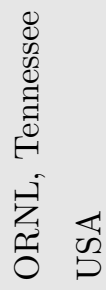 & 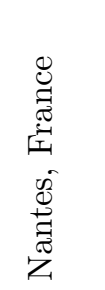 \\
\hline 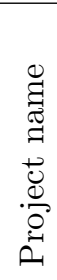 & 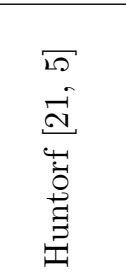 & 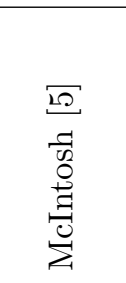 & 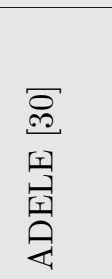 & 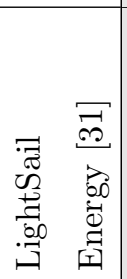 & 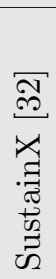 & 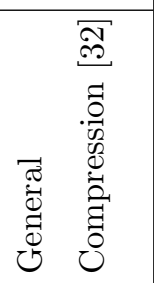 & 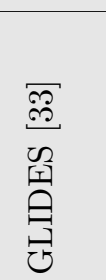 & 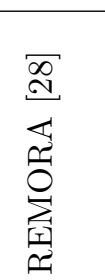 \\
\hline 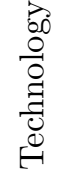 & 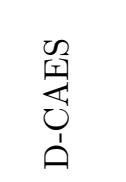 & 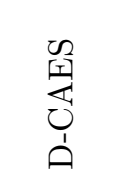 & 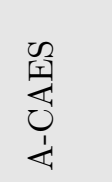 & 岱 & 聓 & 杢 & 聓 & 聓 \\
\hline
\end{tabular}




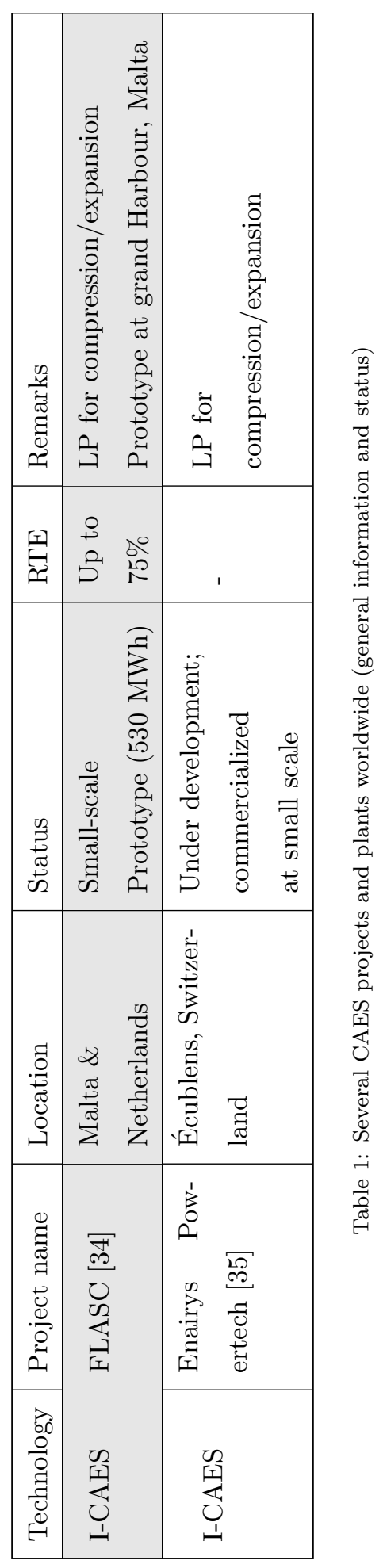



relevant studies and the new developments is lacking.

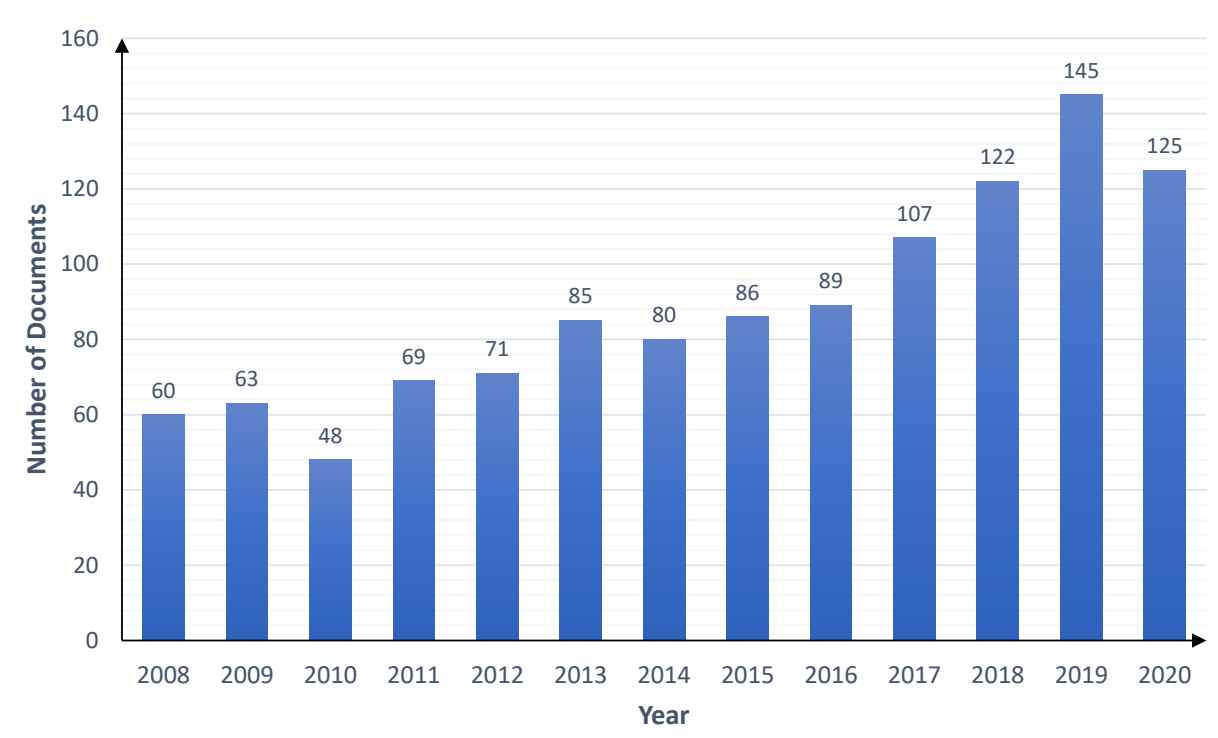

Figure 1: Trend of published documents (journal articles, conference proceedings, book chap-
ters, patents) with "Liquid Piston" in title or abstract for in Dimensions [39] (August 2021)

Figure 1: Trend of published documents (journal articles, conference proceedings, book chap-
ters, patents) with "Liquid Piston" in title or abstract for in Dimensions [39] (August 2021)

In the open scientific literature, the LP concept has also received increasing research attention, indicated by the significantly increasing number of yearly documents since 2008 (Fig. 1). A great number of researches have been devoted to study the heat transfer behaviors through monitoring the evolution of gas temperature [36, 37, 27] and by implementing various techniques to enhance the heat transfer [26, 33]. Few studies have focused on the flow patterns and their transition, showing that the fluid flow hydrodynamics are rather complex and difficult to predict especially when coupled with heat transfer [36, 38, The effects of some design and operational parameters have been studied but their relationships and coherence to the thermofluidic behaviors are still veiled. Moreover, the systematic state-of-art literature review to keep track with all the

This review paper is thereby expected to be the first to gather and survey previous works on LPs for CAES, a research topic with rapid advances in recent years. In particular, a comprehensive and combined knowledge on the thermo- 
1 dynamics, the fluid flow and heat transfer mechanisms within the LP is provided. Special focus is given on the thermal management issue, and measures proposed and implemented by different researchers to enhance the heat transfer, aiming at achieving a highly-efficient LP for I-CAES. The contributions of this paper are important because it provides a technology state-of-the-art and a progress overview of the LP technology covering from the fundamental transport phenomena to the R\&D projects. It may enable interested researchers to timely grasp the latest advancements and existing challenges for the investigation and application of LP technology in future (underwater) CAES systems.

The rest of the paper is organized as follows. The operating principles and the thermodynamic background of the LP are described in section 2 . The fluid flow patterns and the heat transfer characteristics inside the LP during the compression are presented as well. Various techniques to enhance the heat transfer are summarized and compared in section 3. Finally, conclusions and perspectives are presented in section 4.

\section{Liquid piston for energy storage}

LP is in fact not a new concept but can be dated back to the Humphrey pumps in 1906 [40, which is a large internal combustion gas-fuelled LP pump used for large-scale water supply projects. Later on, LPs were also used for Stirling engines and Stirling pumps. The main applications of these configurations were the usage of a LP as a cooler to serve superconducting computers or as a heat pump [41, 42]. In 2009, Van de Ven \& Li first proposed the LP concept for energy storage through an open accumulator [36].

24 2.1. Operating principle

The LP concept, compared to traditional solid piston, is featured by the use of a compression chamber where a liquid (often water) is used to increase or decrease the pressure of a gas (often air or hydrogen). The gas and liquid phases are naturally separated by their density difference, as long as the piston 
advance velocity has no particular effects on the gas-liquid interface. But when

2 a portion of gas becomes trained in the liquid due to the high pressure, the decreased bulk modulus of the liquid could cause the cavitation problem in low pressure areas of the hydraulic system. Van de Ven \& Li [36] proposed to use a blade diaphragm in the liquid column to separate the LP fluid from the working fluid of the hydraulic system, allowing the pressure transfer across the diaphragm with the minimal loss. Other technological alternatives also exist, i.e., by coupling a LP with a solid piston to handle the trained gas problem [43].

The general operation principle of LP, as has already been studied [36] and proved to be feasible for CAES projects [27, 44, 24], is briefly described as follows:

- During the charging stage, the surplus electricity drives the hydraulic pump to fill the liquid into the closed compression chamber from the bottom (Fig. 2æ). Since the chamber is hermetically sealed, the trapped gas in the top region undergoes its pressure increase from $P_{0}$ up to the setting point $P_{c}$ until it is discharged to the gas reservoir by opening the outlet valve. Note that the ratio between $P_{c}$ and $P_{0}$ is called the Compression Ratio (CR).

- During the discharging stage, the compression chamber initially full of liquid is filled with compressed gas released from the gas reservoir. The expansion of the compressed gas in the chamber pushes the liquid to flow back through the turbine to generate electricity (Fig. 2॰). Once a certain volume of gas is present in the chamber, the inlet valve is closed.

Valves are used accordingly to control and switch the process from compression mode to expansion mode by changing the inlet/outlet domains [27, 36].

Besides air or hydrogen, helium was also used as the working gas [45. Piya et al. 46 made a 2D finite difference modeling to test different combinations of liquid (DTE 25 hydraulic fluid (oil) or water) and gas (helium or air). Their results showed that helium/water combination had the best compression effi- 


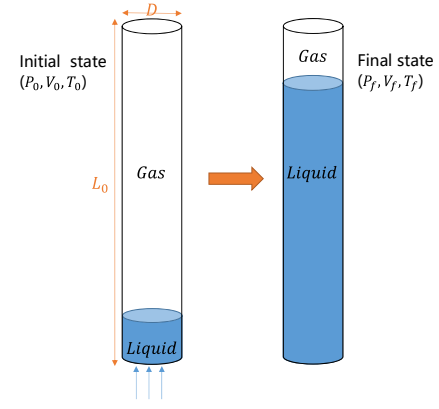

(a)

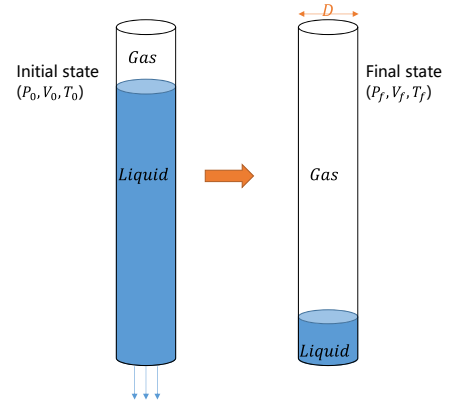

(b)

Figure 2: Operation of LP during the compression (a) and the expansion (b) processes

ciency $\eta_{c}$, going up to $61.9 \%$ compared to $54.31 \%$ for air/water and $23.58 \%$ for air/DTE25 based on the same configuration.

\subsection{Thermodynamic background}

Lemofouet \& Rufer [4] showed that the usage of LP-based CAES can involve 5 different cycles, including the isothermal cycle (A-D path as shown in Fig. 3, the 6 same below), the Joule cycle (A-B-D-E-A: a combination of the adiabatic and 7 isobaric processes), the Otto cycle (A-B-C-D-E-F-A: a combination of adiabatic 8 and isochoric processes) and the polytropic cycle (A-B'-C'-D-F' and A-B'-D9 E'-A). The gray area enclosed in each cycle's path represents the energy losses 10 for that cycle. It can be seen that the isothermal cycle without energy loss is 11 the optimal one among these cycles. The closer the path to the isothermal one the less losses the system generates (Fig. 3). In both closed and open systems, the Joule cycle is more efficient than the Otto cycle for small values of CR [48, 47, 49,. Dib et al. 48, 49, also studied the thermodynamics of different compression/expansion cycles with a LP and showed that a Joule cycle is more adapted for a LP gas compression for energy storage.

In an open-accumulator CAES system air at initial state $\left(T_{0}, P_{0}, V_{0}\right)$ is compressed by a LP through a $P-V$ trajectory $(\zeta)$ to a second state $\left(T_{c}, P_{c}, V_{c}\right)$ with a $\mathrm{CR}=\frac{P_{c}}{P_{0}}$. Then, the compressed air is ejected into the open accumulator and cooled isobarically to a smaller volume $\left(V_{i s o}\right)$, by adding liquid into the bottom 


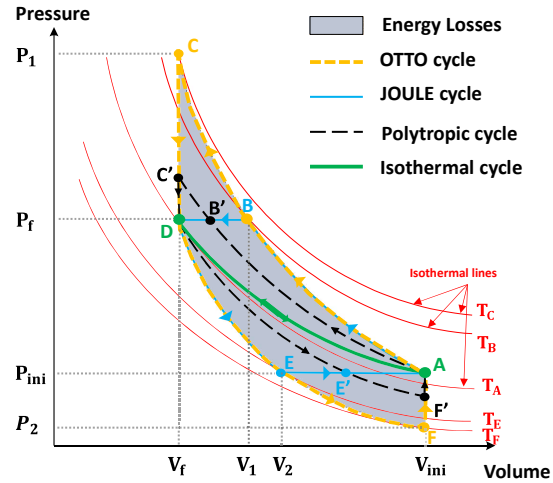

(a)

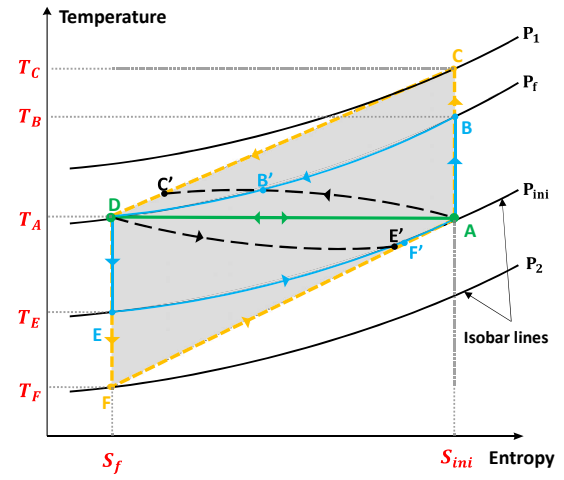

(b)

Figure 3: $P-V$ and $T-S$ diagrams for air compression and expansion processes using different cycles (Otto, Joule, Polytropic and Isothermal). Adapted from [4]

1 of the accumulator until the air reaches the final stored state $\left(T_{0}, P_{c}, V_{i s o}\right)$. For

2 an internally reversible steady flow device, the specific work could be calculated by:

$$
W=\int_{V_{0}}^{V_{c}} P d V
$$

5 The total amount of work input to store the air at the final state is then:

$$
W c_{\text {actual }}=\int_{V_{0}}^{V_{c}} \underbrace{\left(P(t)-P_{0}\right) d V}_{\text {Compression flow }}+\underbrace{\left(1-\frac{1}{\mathrm{CR}}\right)\left(P_{c} V_{c}-P_{0} V_{0}\right)}_{\text {Isobaric cooling }}+\underbrace{\left(P_{c}-P_{0}\right) V_{\text {iso }}}_{\text {Pumping }}
$$

7 After the storage stage, the total potential energy $E_{p}$ that could be extracted

8 from the stored compressed air is shown as the area shaded by the solid vertical 9 lines (Fig. 4a).

$$
{ }_{10} E_{p}=\underbrace{\left(P_{c}-P_{0}\right) V_{\text {iso }}}_{\text {Air discharge to isobaric tank storage }}+\underbrace{P_{0} V_{0}\left(\ln (\mathrm{CR})+\frac{1}{\mathrm{CR}}-1\right)}_{\text {Isothermal expansion }}
$$

The compression efficiency is then defined as Eq. 4 [50]:

$$
\eta_{c}=\frac{E_{p}}{W c_{\text {actual }}}=\frac{\left(P_{c}-P_{0}\right) V_{\text {iso }}+P_{0} V_{0}\left(\ln (\mathrm{CR})+\frac{1}{\mathrm{CR}}-1\right)}{\int_{V_{0}}^{V_{c}}\left(P(t)-P_{0}\right) d V+\left(1-\frac{1}{\mathrm{CR}}\right)\left(P_{c} V_{c}-P_{0} V_{0}\right)+\left(P_{c}-P_{0}\right) V_{\text {iso }}}
$$




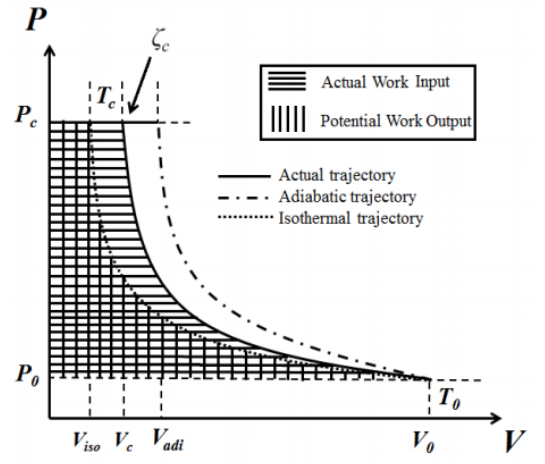

(a)

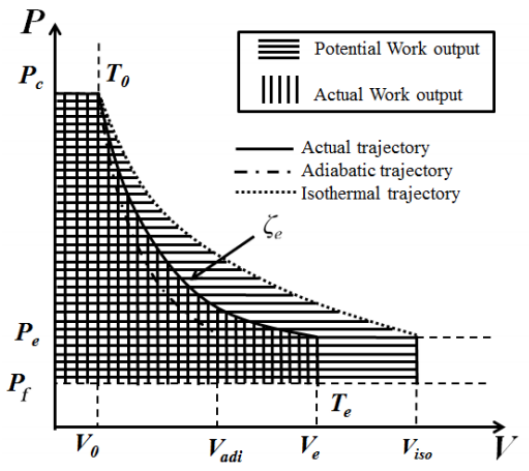

(b)

Figure 4: $P-V$ curves showing compression (a) and expansion (b) trajectories for a LP in an open-accumulator system CAES [50]

1 When the actual compression trajectory approaches the isothermal one, the area shaded by vertical lines gets closer in magnitude to that by the horizontal 3 lines, and $\eta_{c}$ increases. On the contrary, when the trajectory gets closer to the 4 adiabatic one, the difference between those two areas becomes larger and $\eta_{c}$ 5 decreases.

$6 \quad$ For the expansion stage, the stored compressed air $\left(T_{0}, P_{c}, V_{0}\right)$ is firstly 7 ejected from the open-accumulator isobarically and then expanded in the LP at $8\left(T_{e}, P_{e}, V_{e}\right)$. The process also follows a trajectory between the isothermal one 9 and the adiabatic one (Fig. 4b). Similarly, the expansion efficiency $\eta_{e}$ can be calculated in Eq. 5 [50:

$$
\eta_{e}=\frac{W e_{a c t u a l}}{E_{p}}=\frac{\int_{V_{0}}^{V_{e}}\left(P(t)-P_{f}\right) d V+\left(P_{c}-P_{f}\right) V_{0}}{P_{c} V_{0}(\ln (\mathrm{CR}))-\left(P_{f}\left(V_{i s o}-V_{0}\right)\right)+\left(P_{c}-P_{f}\right) V_{0}}
$$

It can be seen from Eq. (4) that the compression efficiency $\eta_{c}$ depends on the compression time as well as the CR. It also depends on the modeled cycle. Since many cycles have been studied, different formulas to calculate the efficiencies exist. Patil \& Ro [51] defined compression/expansion formulas (Eqs. 6 and 7) 
only related to $\mathrm{CR}$ and $n$ the polytropic index :

2

4

5

6

8

$$
\begin{gathered}
\eta_{c}=\frac{\ln (C R)+\frac{1}{\mathrm{CR}}-1}{\frac{\mathrm{CR}^{\frac{n-1}{n}}-1}{n-1}+\mathrm{CR}^{-\frac{1}{n}}-1+(\mathrm{CR}-1)\left(\mathrm{CR}^{\frac{-1}{n}}-\frac{1}{\mathrm{CR}}\right)} \\
\eta_{e}=\frac{1-\frac{\left(\frac{1}{\mathrm{CR}}\right)^{\frac{n-1}{n}}}{n-1}-\left(\frac{1}{\mathrm{CR}}\right)^{\frac{n-1}{n}}+\frac{1}{\mathrm{CR}}}{\ln (\mathrm{CR})+\frac{1}{\mathrm{CR}}-1}
\end{gathered}
$$

Mutlu \& Kiliç [52] have numerically examined the effect of piston speed, the CR and the cylinder geometry on $\eta_{c}$ and required power of a LP. It was found that the $\eta_{c}$ decreased from $87.93 \%$ to $68.89 \%$ when CR increased from 5 to 80 . The piston velocity had only a small impact $(0.5 \%)$ on $\eta_{c}$ once a certain velocity $\left(U_{\text {pist }}=0.05 \mathrm{~m} / \mathrm{s}\right)$ had been reached. Decelerating the piston velocity at higher pressures did not affect the total input work nor the efficiency of the process. Their study recommended to use long cylinders with small diameters to achieve a higher $\eta_{c}$, e.g., up to $91.42 \%$ with the proper length/diameter ratio $L / D$ [52. For low pressure compression, an important flow rate (velocity) is usually imposed to compensate the power level and the system performance. Both the convective heat transfer coefficient and the frictional pressure drop will increase with the increasing piston advance velocity, leading to higher energy density at the cost of higher hydraulic loss. The same thing applies to the L/D ratio and a trade-off needs thereby to be made.

\subsection{Flow patterns during air compression}

The fluid flow regime inside a LP column during dynamic operation is rather complex, involving unsteady compressible multiphase flow (liquid/gas) with conjugated heat transfer. The Reynolds number $R e$ is usually used to characterize the flow pattern within a cylindrical column (uniform cross-sectional area):

$$
R e_{L}=\frac{\rho_{L} U D}{\mu_{L}}=\frac{U D}{\nu_{L}}
$$

Or :

$$
R e_{G}=\frac{\rho_{G} U D}{\mu_{G}}=\frac{U D}{\nu_{G}}
$$


a

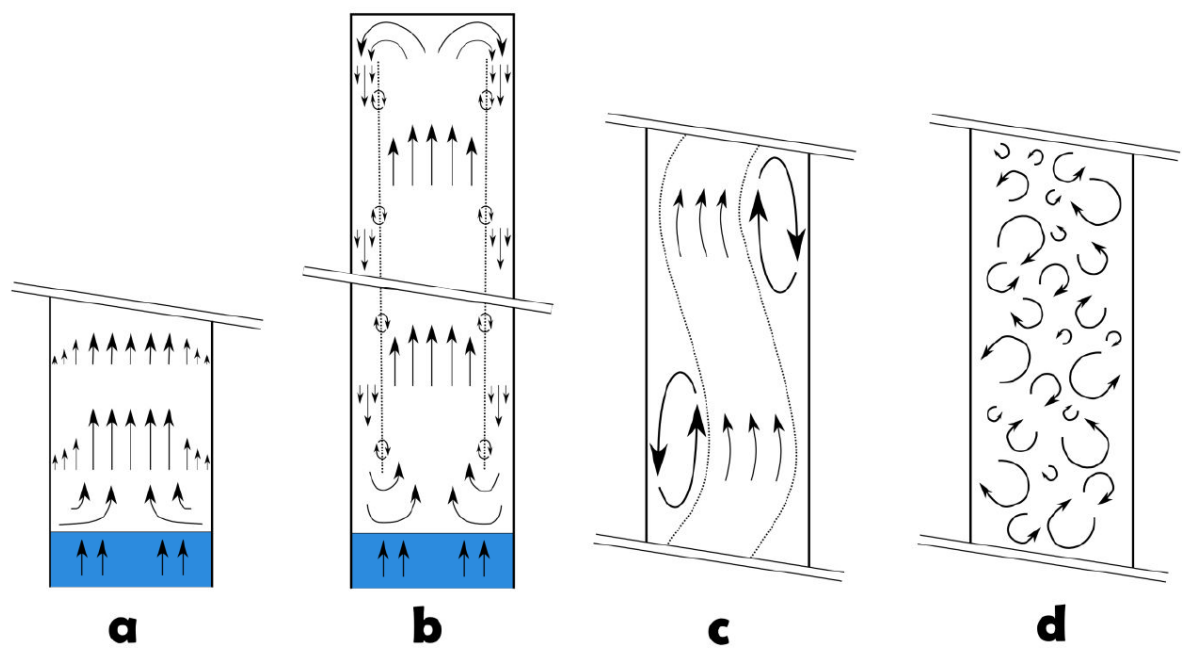

Where $\rho$ is the density of the fluid, $U$ is the advance velocity (of the interface) in the piston column, $D$ is the (hydraulic) diameter of the column, $\mu$ and $\nu$ the dynamic and kinematic viscosity, respectively.

However, one should distinguish the $R e$ for the liquid phase $\left(R e_{L}\right)$ and that for the gas phase $\left(R e_{G}\right)$. Since a constant liquid volume flow rate is often assumed by the liquid pump, the liquid velocity as well as the $R e_{L}$ are considered thereby as constant during the compression process. On the contrary, the gas flow is much more complex than a simple pipe flow because the gas does not have the same velocity as water all over the piston column, as reported by Mutlu \& Kiliç 52] and Schober et al. [45. It has been observed by Neu et al. [53, 27] that during compression many re-circulation zones could appear next to the walls (upper, bottom and lateral) of the piston column. The numerical results of Gouda et al. 54] also shown that the maximum local velocity of air could reach 8 times the velocity of water. The gas phase actually undergoes regime transition from laminar to turbulent along with the advancement of the piston (air and water are the working fluids), as illustrated in Fig. 5.

Figure 5: Evolution of air flow pattern along with the advancement of the water during the compression operation 53

At first, an ascending central air flow becomes established during the short 
1 start-up period of compression (Fig. 5 (a)). This central rising flow having a velocity magnitude greater than the water velocity will then disturb the stationary air at the upper part of the column, initiating the air movement. In a little while, the central rising air flow occupies the entire compression chamber while the falling flow occurs close to the walls of the column (Fig. 5 (b)). Recirculation zones are thereby present at both ends of the compression chamber, i.e. at the column head where the central rising air is deviated to the outer periphery and at the air-water interface where the descending air rejoins toward the center of the column. At the boundary between the ascending and descending air flows, small instabilities would cause small amplitude of movements between the two velocity regions. When the central air velocity is significantly higher than the water velocity, the Rayleigh-Taylor instabilities [55] become stronger and will trigger swirling flows and vortices (Fig. 5 (c)). This transition regime is rather short and in a brutal way, the global structure of the air flow disintegrates into a multitude of small vortices as shown in Fig. 5 (d), indicating the turbulent feature of the flow. Such transition of flow regime has also been confirmed by Gouda et al. 54 through CFD (Computational Fluid Dynamics) simulation of the compression process with the VOF (Volume-Of-Fluid) model.

19 Many other formulations of Re number have therefore been proposed to 20 better characterize the gas flow regimes and their transition. For example, ${ }_{21}$ Adair et al. [56] and Liu \& Zhou [57] used the transient equivalent diameter ${ }_{22}$ and the swirl velocity $\left(\omega_{g}\right)$ instead of the averaged piston speed:

$$
R e=\frac{\rho(D / 2)^{2} \omega_{g}}{\mu}
$$

${ }_{24}$ Van de Ven \& Li 36] used the fully-developed pipe flow model to calculate the ${ }_{25} \operatorname{Re}(\mathrm{Eq} .11)$ :

$$
R e=\frac{U_{a v e} D}{\nu}
$$

${ }_{27}$ where $U_{\text {ave }}$ is the average gas velocity, estimated as half of the piston (liquid)

${ }_{28}$ velocity and $D$ is the characteristic length (diameter of the piston).

Neu et al. 27, 38, observed that the transition from laminar to turbulent flow seems to happen at different stroke times depending on the operational 
conditions $\left(D, L, U_{\text {pist }}\right.$, etc.). Their experimental measurements of air temperature in the compression column also showed a switch from a slow evolution to a fast oscillation during the compression. An empirical correlation has been proposed to predict the position of the piston front at the moment of regime transition (Eq. 12):

${ }_{6} \quad L_{t r}^{*}=\left(-0.0344 L_{0}+109 U_{\text {pist }} D^{2}+\frac{0.0227}{D}\right)\left(\frac{P_{0}}{P_{\text {ref }}}\right)^{-0.645 * \sqrt{U_{\text {pist }}}}$

Where $L_{0}$ is the initial piston length, $L_{t r}^{*}$ is the non-dimensional piston position (water/air interface) when the transition occurs, $U_{\text {pist }}$ is the piston inlet velocity, $P_{r e f}$ is the reference pressure, generally equal to the atmospheric pressure and $P_{0}$ the initial pressure. This correlation has been experimentally verified within the range of $P_{0}=101325 \mathrm{~Pa}, 2 \mathrm{~m} \leq L_{0} \leq 6 \mathrm{~m}, 0.08 \mathrm{~m} / \mathrm{s} \leq$ $U_{\text {pist }} \leq 1.25 \mathrm{~m} / \mathrm{s}$ and $3 \times 10^{-2} \mathrm{~m} \leq D \leq 10^{-1} \mathrm{~m}$.

\subsection{Heat transfer analysis}

The heat transfer characteristics inside a LP column is also complex, due to various heat transfer modes involved. The increasing gas (air) temperature during the compression will cause the heat transfer between the gas and liquid which are in direct contact. Moreover, the convection heat transfer, which is the most dominant, occurs between the piston wall and the gas or/and liquid. Depending on the advancement of the gas-liquid interface, the flow regimes, the thermal resistance of wall and the temperature of the external environment, the liquid may absorb heat from the wall, or vice-versa, release the heat towards the wall.

Nikanjam \& Greif [58] measured the wall temperature variation of a LP to estimate the heat flux. The liquid chosen was oil, and two gases (argon and air) were compressed with a thin film gauge placed at the end wall of the compression chamber. Only conduction heat transfer was supposed to happen at the wall. Kermani \& Rokni 59] developed a detailed heat transfer model considering both the heat transfer through the gas-liquid interface and through the wall. Some 
1 critical parameters have been identified to maximize the amount of heat that can 2 be extracted from the compressed gas for a hydrogen compression technology.

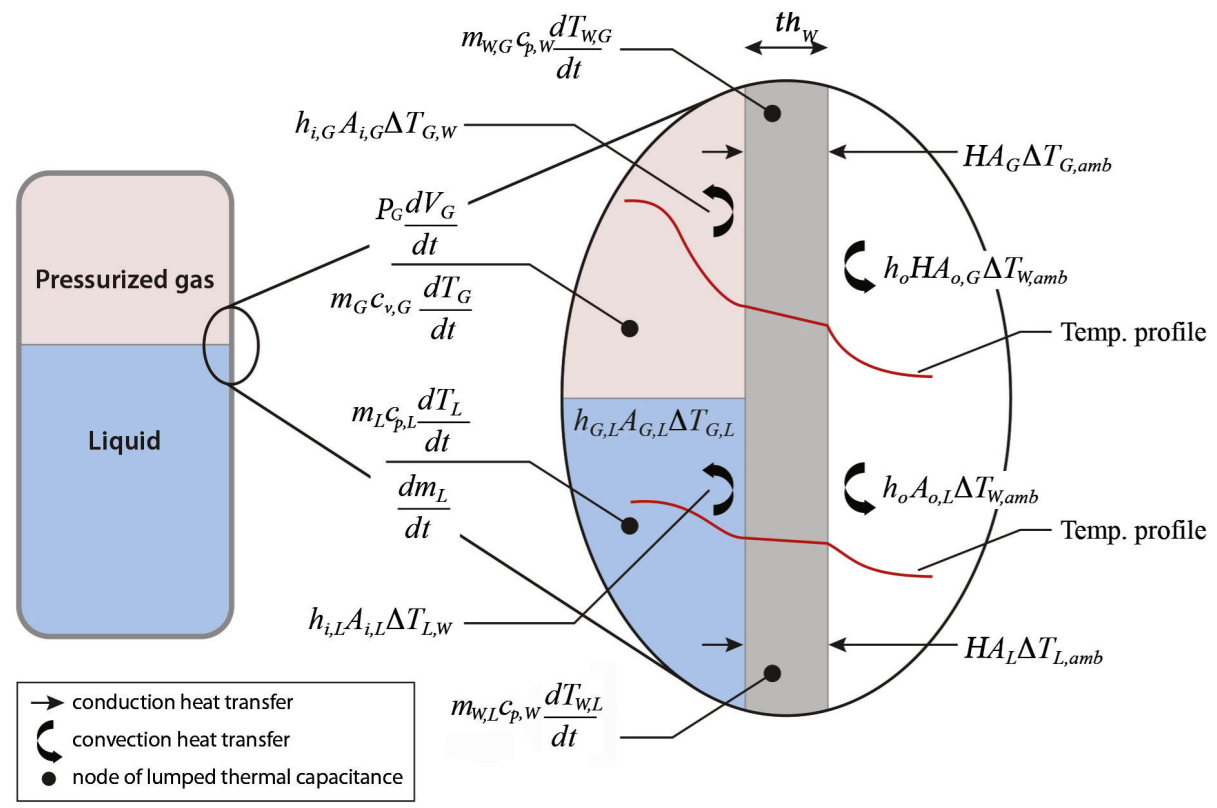

Figure 6: Heat transfer modeling for LP compression/expansion, including the convection between the gas and liquid through the interface, the convection at the inner and outer walls of the piston column and the conduction through the wall. Adapted from 22

A detailed modeling of heat transfer inside the LP has been performed by 4dukomaiya et al. 22, as shown in Fig. 6. It has been supposed that the upper 5 wall temperature in contact with gas has a uniform temperature $\left(T_{W},_{G}\right)$ and the 6 one in contact with liquid $\left(T_{W}, L\right)$ is also uniform. These temperatures evolve in 7 time as the piston front moves upward (compression) or downward (expansion). 8 The internal energy variation of the gas or liquid phase can be calculated by 9 Eq. 13 or Eq. 14, respectively. Note that Redlich-Kwong equation of state was 10 used to model the gas inside the column. 


$$
\underbrace{m_{G} c_{v, G} \frac{d T_{G}}{d t}}_{\begin{array}{c}
\text { change of } \\
\text { the gas energy }
\end{array}}=\underbrace{-h_{G, L} A_{G, L}\left(T_{G}-T_{L}\right)}_{\begin{array}{c}
\text { heat transfer } \\
\text { with the liquid }
\end{array}} \underbrace{-H A_{G}\left(T_{G}-T_{a m b}\right)}_{\begin{array}{c}
\text { heat transfer with ambient } \\
\text { through the wall }
\end{array}}-\underbrace{P_{G} \frac{d V_{G}}{d t}}_{\text {boundary work }}
$$

$$
\underbrace{m_{L} c_{p, L} \frac{d T_{L}}{d t}}_{\begin{array}{c}
\text { change of } \\
\text { the liquid energy }
\end{array}}=\underbrace{h_{G, L} A_{G, L}\left(T_{G}-T_{L}\right)}_{\begin{array}{c}
\text { heat transfer } \\
\text { with the gas }
\end{array}} \underbrace{-H A_{L}\left(T_{L}-T_{a m b}\right)}_{\begin{array}{c}
\text { heat transfer with ambient } \\
\text { through the wall }
\end{array}} \underbrace{+\dot{m}_{L} c_{p, L}\left(T_{a m b}-T_{L}\right)}_{\text {mass flow }}
$$

Where $m$ is the mass, $c_{v}$ and $c_{p}$ are the specific heat capacity at constant volume and constant pressure, respectively, $h$ is the heat transfer coefficient, $A$ is heat transfer surface area, $H$ is the global heat transfer coefficient and $\dot{m}=\frac{d m}{d t}$ is the mass flow rate. The subscripts $G, L$ and $a m b$ represent the gas phase, the liquid phase and the ambient, respectively.

The variation of wall temperature in contact with the gas phase or liquid 9 phase can be calculated as:

$$
\underbrace{m_{W, G} c_{p, W} \frac{d T_{W, G}}{d t}}_{\begin{array}{c}
\text { change of } \\
\text { wall energy }
\end{array}}=\underbrace{h_{i, G} A_{i, G}\left(T_{G}-T_{W, G}\right)}_{\begin{array}{c}
\text { heat transfer between gas } \\
\text { and inner wall }
\end{array}} \underbrace{-h_{o} A_{o, G}\left(T_{W, G}-T_{a m b}\right)}_{\begin{array}{c}
\text { heat transfer between outer } \\
\text { wall and ambient }
\end{array}}
$$

$$
\underbrace{m_{W, L} c_{p, W} \frac{d T_{W, L}}{d t}}_{\begin{array}{c}
\text { change of } \\
\text { wall energy }
\end{array}}=\underbrace{h_{i, L} A_{i, L}\left(T_{L}-T_{W, L}\right)}_{\begin{array}{c}
\text { heat transfer between liquid } \\
\text { and inner wall }
\end{array}} \underbrace{-h_{o} A_{o, L}\left(T_{W, L}-T_{a m b}\right)}_{\begin{array}{c}
\text { heat transfer between outer } \\
\text { wall and ambient }
\end{array}}
$$

Where the subscripts $i, o$ and $W$ represent the inner surface, the outer surface and the wall, respectively. The global heat transfer capacity $H A_{G}$ or $H A_{L}$ is calculated based on the sum of effective thermal resistances according to the convection on the inner and outer wall surfaces and the conduction through the wall.

$$
H A_{G}=\frac{1}{\left(\frac{1}{h_{i, G} A_{i, G}}\right)+\left(\frac{t h_{W}}{\lambda_{W} A_{a v e, G}}\right)+\left(\frac{1}{h_{o} A_{o, G}}\right)}
$$

$$
H A_{L}=\frac{1}{\left(\frac{1}{h_{i, L} A_{i, L}}\right)+\left(\frac{t h_{W}}{\lambda_{W} A_{a v e, L}}\right)+\left(\frac{1}{h_{o} A_{o, L}}\right)}
$$


1 where $t h_{W}$ is the thickness of the wall and the subscribe ave stands for average.

Kermani \& Rokni [59] developed a LP model based on the first law of thermodynamics to predict the evolution of temperature and pressure. The amount of heat transferred from the gas (hydrogen) towards the wall was estimated according to different heat transfer correlations. The results showed small changes in hydrogen temperature, between $0.2 \%$ and $0.4 \%$, compared to the adiabatic case. Patil et al. 37 experimentally tested a LP compressor with different chamber materials and various stroke times of compression. It was observed that the heat transfer rate increased with the increasing piston velocity but at the expense of additional compression work and a higher gas temperature. The convective heat transfer coefficient was observed to be high at the initial phase of the compression but then decreased to a stable value. In fact, the interior convective heat transfer coefficient $h_{i, G}$ for the gas phase is a key parameter that should be carefully estimated in the modeling of heat transfer behaviors of LP. For engineering applications, it is usually a convenient way to present and compare the results in terms of the dimensionless Nusselt number $N u$. Considering that $h_{i, G}$ varies along the piston (tube), it is usually the average value of $h_{i, G}$ used to calculate the $N u$ :

$$
N u_{D}=\frac{1}{L_{0}} \int_{0}^{L_{0}} \frac{D}{\lambda} h_{i, G}(L) d L=\frac{h_{i, G} D}{\lambda}
$$

Where $\lambda$ is the thermal conductivity of gas. Many correlations have been proposed to estimate the heat transfer performance of the working gas, mainly for a reciprocating piston application or for a compression fluid in tubes. In these correlations the $N u$ number is usually written as a function of the Reynolds number Re and the Prandtl number Pr, in a generic form shown in Eq. 20

$$
N u=A \operatorname{Re}^{a} \operatorname{Pr}^{b}\left(\frac{\mu}{\mu_{0}}\right)^{c}
$$

Where $A, a, b$ and $c$ are constants fitting different working conditions. $\mu$ and $\mu_{0}$ are the fluid viscosity at fluid's average temperature and at the heat transfer boundary surface temperature, respectively. 
Some widely used empirical $N u-R e$ correlations are listed in Table 3 Among them, Dittus \& Boelter [60] correlation was proposed for fully developed turbulent flow in circular tubes, with smooth surfaces and moderate temperature difference between the wall and fluid mean temperature. Sieder \& Tate [61 extended the Dittus \& Boelter correlation by taking the wall effect into account for the condition of large temperature difference between the wall and the fluid. Hamilton 62 proposed a new correlation more adapted to the compressor chamber, especially for $L / D \leq 60$. Likewise, Annand [63, Adair et al. [56, Liu \& Zhou [57] and Hsieh \& Wu 64] proposed other correlations for the reciprocating compressors based on their proper experimental data.

More recently, Van de Ven \& Li [36] numerically compared the evolution of $R e, N u$ and gas temperature in a single stage LP and in a reciprocating solid piston. Their results showed that the LP could have significantly lower $N u$ but much higher $h_{i, G}$ than that of the solid piston, mainly due to a smaller diameter of the compression chamber. Moreover, the LP can reach a near-isothermal compression process which can hardly be achieved by the solid piston. Two $\mathrm{Nu}$-Re correlations were proposed, one for laminar flow regime (Eq. 21) and the other for turbulent flow regime (Eq. 22) 65.

$$
\begin{aligned}
& N u=0.664 \operatorname{Re}^{1 / 2} \operatorname{Pr}^{1 / 3} \\
& N u=0.023 \operatorname{Re}^{0.8} \operatorname{Pr}^{0.3}
\end{aligned}
$$

Neu et al. 27] experimentally studied a LP prototype for CAES. A set of configurations were tested with the column diameter $D$ varying from $30 \mathrm{~mm}$ to $100 \mathrm{~mm}$ and the piston length $L_{0}$ from $2 \mathrm{~m}$ to $6 \mathrm{~m}$. Based on the data of 73 compression tests, $N u$-Re correlation has been proposed for the laminar flow regime (Eq. 23) and for the turbulent flow regime (Eq. 24), respectively. Good agreement could be achieved between the correlation prediction and the experimental data [27. 


$$
\begin{aligned}
& N u_{\text {lam }}=6.67\left(\operatorname{Re}_{D} \operatorname{Pr} \frac{D}{L}\right)^{0.36} \\
& N u_{\text {turb }}=6.17\left(\operatorname{Re}_{D} \operatorname{Pr} \frac{D}{L}\right)^{0.48}
\end{aligned}
$$

The transition from $N u_{\text {lam }}$ to $N u_{\text {turb }}$ could be determined by using the non-dimensional formula shown in the previous section (Eq. 12).

\section{Heat transfer enhancement technologies for LP}

The description in the above sections clearly indicates that how to handle the heat transfer to approach an isothermal gas compression and expansion is actually a key issue to increase the LPs efficiency and the RTE of CAESs Therefore, different techniques for Heat Transfer Enhancement (HTE) have been proposed and implemented within the LPs. This section introduces several representative types of HTE with special focus on the concept, the efficiency increase and the related $\mathrm{Nu}$-Re correlation.

\subsection{Spray injection}

Spray injection concept can be utilized to increase the heat transfer during the compression/expansion process where a high pressure spray of water droplets is injected into the top of LP column. The water droplets having a high heat capacity, scattered in the air, can absorb heat from the air during compression or inject heat into air during expansion, as explained in Fig. 7. The mean droplet diameter (MDD), the mass loading (ML defined as the ratio of water spray mass injected into a cycle and the mass of dry air drawn into the piston chamber) and the injected spray temperature are key operational parameters that determines the efficiency of this thermal management concept.

Qin \& Loth [43] studied the efficiency of LP with droplet spray through a 1-D simulation validated with experimental data. Two ways of spray injection were considered: premixed injection upstream of the intake valve and direct injection within the compression chamber. For the direct injection, the nozzles 


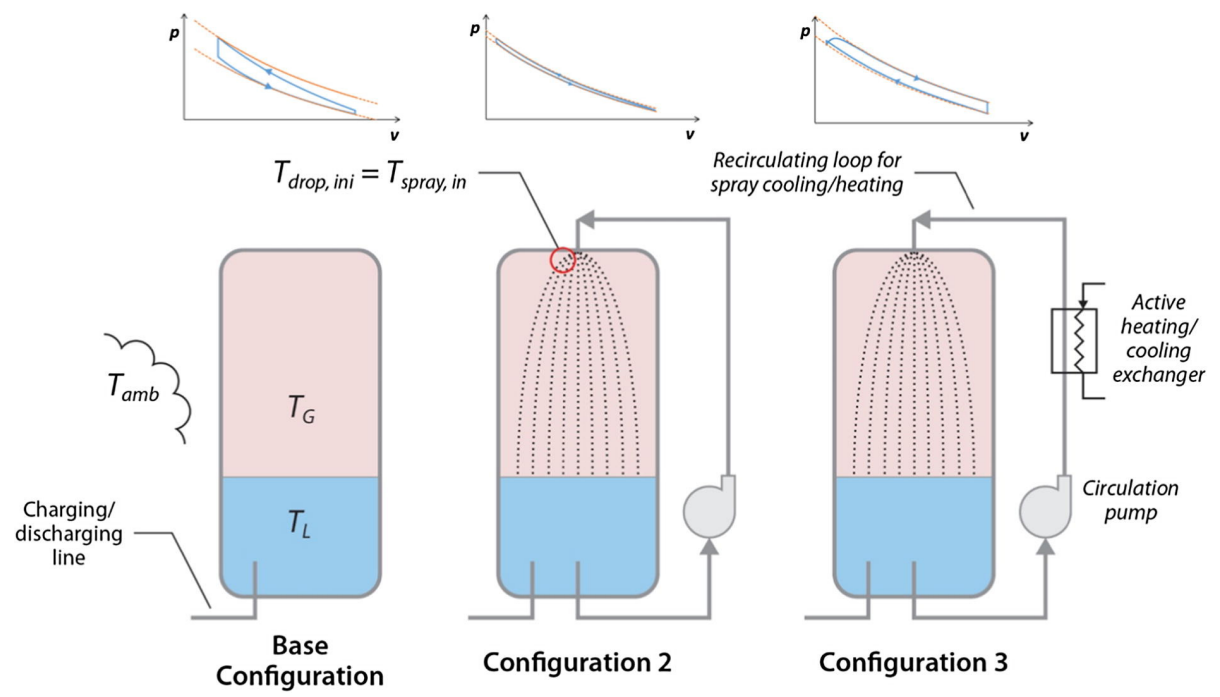

Figure 7: Investigated alternative liquid spray configurations of GLIDES system [22]

1 were installed inside the piston to inject and uniformly distribute the liquid droplets. For the premixed injection, the nozzle was placed upstream the intake valve. Various conditions were tested including a CR ranging from 6 to 12, a MDD of 10, 20, 50 and $100 \mu m$ and a ML of 0.5, 1, 2 and 5. Their simulation results showed that the direct injection concept of spray cooling $(\mathrm{CR}=10$; $\mathrm{MDD}=20 \mu m ; \mathrm{ML}=1$ ) could reach a $\eta_{c}$ higher than $95 \%$ compared to about $771 \%$ for adiabatic compression. When ML increased to 5 , the $\eta_{c}$ could be fur8 ther augmented up to $98 \%$, as shown in Fig. 8. A Nu-Re correlation (Eq. 9 25) based on Ranz-Marshall form [66] was used to estimate the heat transfer characteristics of LP with liquid spray.

$$
N u=2+0.6 \operatorname{Re}^{1 / 2} \operatorname{Pr}^{1 / 3}
$$

With a similar configuration, Zhang et al. 67] only obtained a $10 \%$ gas temperature abatement compared to the adiabatic case, mainly due to a small $L / D \sim 1$. Guanwei et al. 68 has built an experimental setup to test the spray cooling technique for LP. Experiments have been done in the summer and in the winter with different ambient temperatures to compare the effects of the nozzle diameter $(0.1-1 \mathrm{~mm})$ and spray droplet diameters $(10-100 \mu \mathrm{m})$ on the 


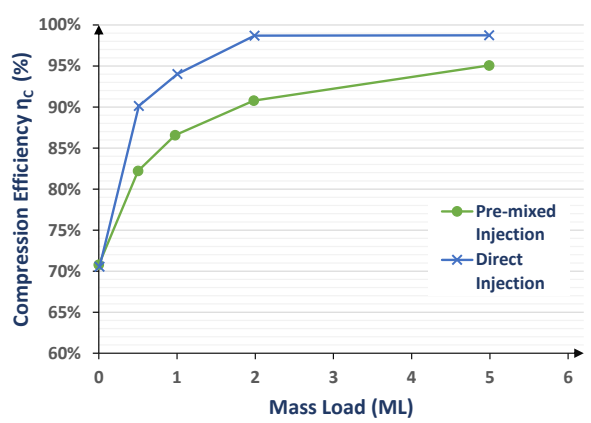

(a)

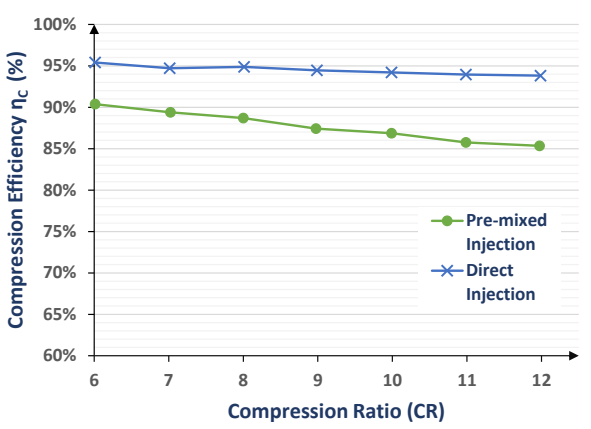

(b)

Figure 8: Efficiency increase of Liquid Piston by the liquid spray injection. (a) Compression Ratio $(\mathrm{CR})=10$ and variable Mass Loading $(\mathrm{ML})$; (b) variable CR, Mean Droplet Diameter $(\mathrm{MDD})=20 \mu \mathrm{m})$. Adapted from 43

heat transfer rate and thus on the $\eta_{c}$. The best $\eta_{c}(92,8 \%)$ has been achieved with $\mathrm{CR}=2$ and $D=0.3 \mathrm{~mm}$ nozzle diameter. Further increasing the nozzle diameter required a higher work to generate the spray due to higher mass of water injected in the piston.

$5 \quad$ Odukumaiya et al. 22] numerically and experimentally studied the effect of 6 liquid spray for enhancing the heat transfer. Three configurations were tested as shown in Fig. 7: without liquid spray (base configuration), liquid spray with 8 or without heat regeneration. The tests conducted under the base configuration 9 showed a temperature rise up to $40 \mathrm{~K}$ during compression and a fall of 15 10 K during expansion. The introduction of spray droplets could attenuate the temperature variation, to $13 \mathrm{~K}$ (for configuration 2) and $3 \mathrm{~K}$ (for configuration 3), respectively. Nevertheless, this active heating/cooling for regulating the temperature of spray via an external heat exchanger needs extra energy input. Note that the same correlation of Eq. 25 has been used to model the heat transfer.

The impacts of other parameters, i.e., the compression time, the injection pressure and the spray angle on the heat transfer and the efficiency have also been studied by Patil et al. 69, 70. Their results showed the positive effect of injection pressure when it increased from $10 \mathrm{psi}(69 \mathrm{kPa})$ to $30 \mathrm{psi}(483 \mathrm{kPa})$, 
but the benefit became marginal beyond $30 \mathrm{psi}$. The nozzle angle at $60^{\circ}$ was shown to be the most efficient configuration whereas the compression time had no significant impact.

The spray injection concept has proven its efficiency in both multi-stages and one stage compressions especially for obtaining a trade-off between power density and efficiency. For one stage compression, the tested CR is relatively low (maximum 10), which are not adapted for an industrial application. Another issue is the pumping power for the spray injection at high pressures and high flow rates [22]. The trade-off between all these factors should be determined carefully.

\subsection{Porous media}

Another largely used measure to enhance the heat transfer is the porous me- 


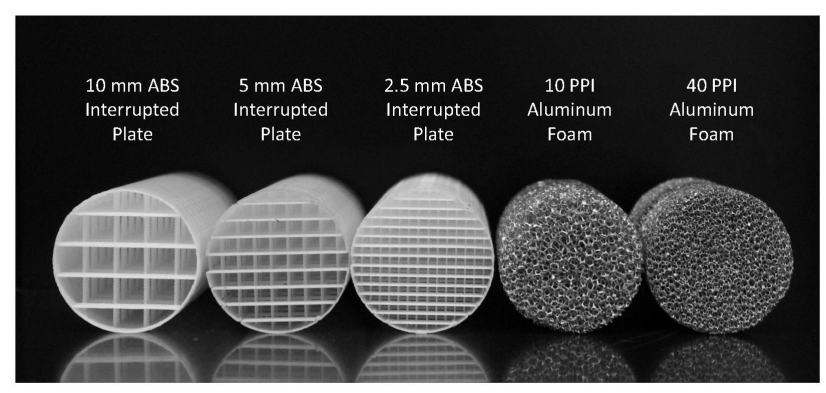

Figure 9: Five types of porous inserts used in compression/expansion experiments [50, including 3 Acrylonitrile Butadiene Styrene (ABS) interrupted-plates with $2.5 \mathrm{~mm}, 5 \mathrm{~mm}$ and $10 \mathrm{~mm}$ spacing between plates and 2 aluminium foams with 10 and 40 pores per inch (PPI)

1 the heat transfer in their studied geometry with porous media inserts. These 2 correlations were proposed by many researchers, including Wakao \& Kaguei 3 [75], Kuwahara et al. [76], Zukauskas [77, Nakayma et al. [78, Kamiuto \& 4 Yee [79] and Fu et al. 80] (cf. details in Table 3). Among them, the Kamiuto 5 \& Yee correlation [79] fitted the best their experimental results with 10 PPI 6 (Pores Per Inch) insert, and was then chosen for a further numerical study [81. 7 A new correlation has been proposed based on the obtained simulation results 8 (Eq. 26):

$$
N u=9.700+0.0879 \operatorname{Re}_{D h}^{0.792} \operatorname{Pr}^{1 / 3}
$$

Later on, an improved correlation has also been proposed (Eq. 27) [73:

$$
N u=8.456+0.325 \operatorname{Re}_{D h}^{0.625} \operatorname{Pr}^{1 / 3}
$$

${ }_{12}$ Where $R e_{D h}$ is the Reynolds number based on the hydraulic diameter $D_{h}$ of 13 the piston column.

${ }_{14}$ Besides, the Stanton number $(S t)$ and a dimensionless heat flow rate term $15\left(Q^{*}\right)$ were used to characterize the effect of porous inserts.

$$
S t=\frac{h_{i, G}}{\rho c_{p} \frac{U}{2}}
$$

${ }_{17}$ A linear relation $S t$ versus $Q^{*-1}$ has been found [73], written as:

$$
-S t=a\left(Q^{*-1}\right)+b
$$



density.

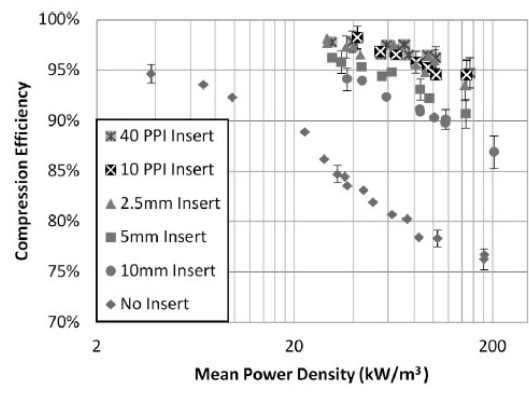

(a)

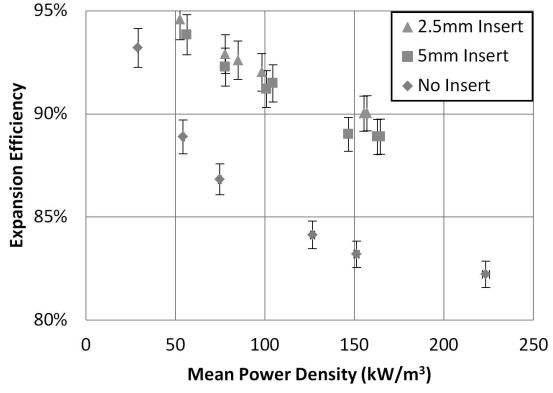

(b)
Figure 10: Comparison of compression/expansion efficiencies with or without the porous media inserts [50]. (a). Compression efficiency vs. power density $(\mathrm{CR}=10)$; (b). Expansion efficiency vs. power density (expansion ratio=6)

More recently, a LP structure with a two layer porous medium was proposed mal compression. It was reported that this configuration could also reduce the pressure and the compression work needed. 
A thermodynamic and heat transfer analysis was conducted by Khaljani et al. 83] to evaluate the use of porous media as an effective for thermal management. The porous medium has been modeled as metal parallel plates inserted in the piston column. The results showed that the inclusion of five and nine plates could reduce the final temperature of the air by $15 \mathrm{~K}$ and $20 \mathrm{~K}$, respectively, compared to the base case without plate inserts. The porous insert also had a significant influence on the wall temperature and on the flow pattern evolution. With 9 plates insert, the $\eta_{c}$ could be increased by $2 \%$, going from $86.91 \%$ for the base case to $88.91 \%$. Nevertheless, the energy storage capacity would decrease, since a part of the piston volume was occupied by the porous media, leaving smaller space for the gas phase.

In brief, porous media insert could be considered as the most widely used HTE technology for LP, adapted to different CR for both the compression and the expansion. It can offer high power densities while maintaining the efficiency and can be easily combined with the other HTE concepts as will be introduced in following sub-sections. Further researches could be focused on finding the optimal geometries of the porous media by using shape or topology optimization methodologies 84.

\subsection{Optimal trajectories}

Another proposed HTE concept consists in optimizing the manner of air compression from the view point of finite-time thermodynamics by choosing the best trajectory $(\zeta)$ (Fig. 4), with the purpose of significantly improve the energy storage/generation capacity. Moreover, it tries to find the trade-off between the HTE and the pressure drop increase by imposing a pressure-linked flow rate, i.e., a high flow rate at the beginning of the compression/expansion but gradually decreasing with time.

Saadat et al. 85] proposed a general numerical approach to determine the optimal compression profile by using more general heat transfer models. The viscous friction and system constraints were also considered in the optimization process. A fully developed laminar pipe flow model was used to estimate the 
heat transfer coefficient inside cylinders with high $L / D>>1$ (Eq. 30):

$$
h=3.66 \frac{\lambda}{D}
$$

3 An average Nusselt number $N u_{\text {ave }}$ was also proposed based on $R e_{\text {air,ave for }}$ 4 cylinders with small $L / D \sim 1$ where the flow is supposed to still be laminar 5 (Eq. 31):

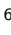

$$
\begin{gathered}
N u_{\text {ave }}=0.664 R e_{\text {air }, \text { ave }}^{1 / 2} \operatorname{Pr}^{1 / 3} \\
R e_{\text {air }, \text { ave }}=\frac{\rho_{\text {air }} D U_{\text {air }, \text { ave }}(t)}{2 \mu_{\text {air }}}=\frac{2 m}{\pi D \mu_{\text {air }}} \frac{U_{\text {air }, \text { ave }}(t)}{L_{0}-L(t)}
\end{gathered}
$$

Where $U_{\text {air,ave }}(t)$ is the air average velocity and $L(t)$ is the liquid/air interface position. Based on the Pareto optimization procedure, their results 85 showed that the optimal compression profile increased the storage power up to $10 \%$ for a $\eta_{c}$ of $90 \%$ compared to the A-PI-A (Adiabatic-PseudoIsothermal-Adiabatic process) and more than $40 \%$ when compared to a conventional compression profile such as sinusoidal or constant speed compression trajectories (Fig. 11). Several other trajectories were tested and compared. Note that the study was limited to a relatively small $\mathrm{CR}=10$, the effect of optimal trajectory could be expected to be more significant at higher CR and with more complex geometries.

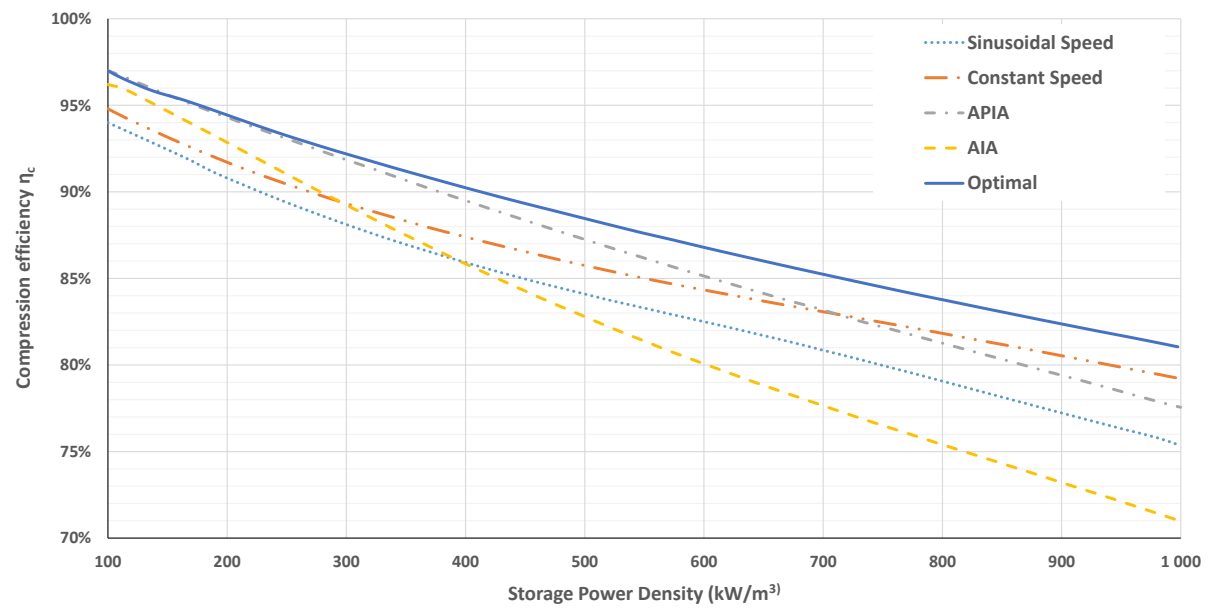

Figure 11: Comparison on the efficiency as a function of storage power density for different compression trajectories $(\mathrm{CR}=10)$. Adapted from 85 


\subsection{Honeycomb geometry}

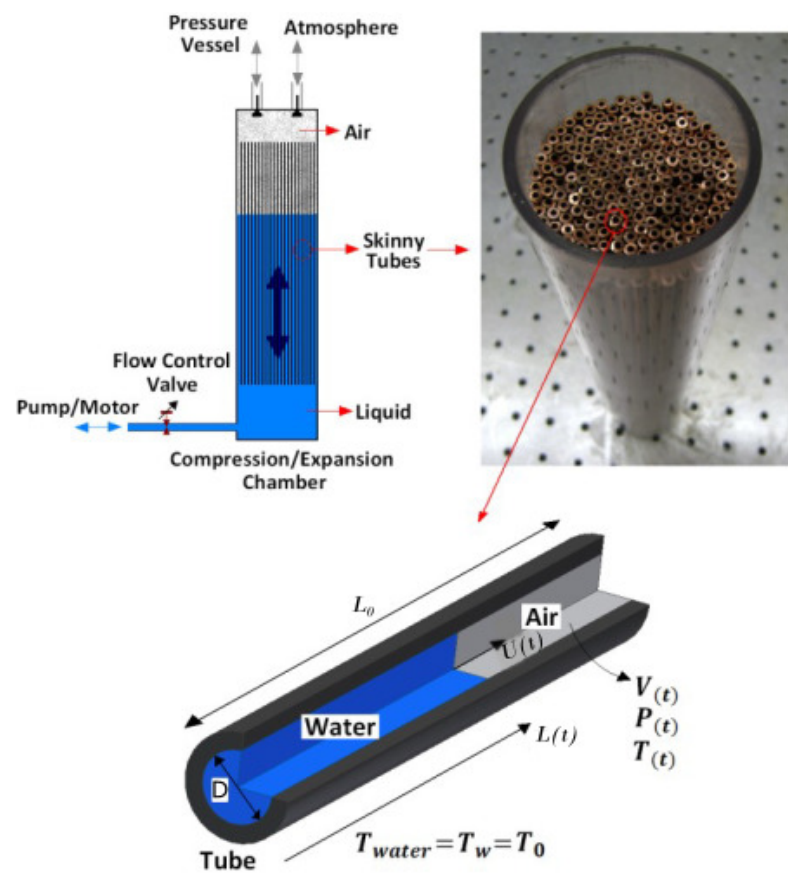

(a)

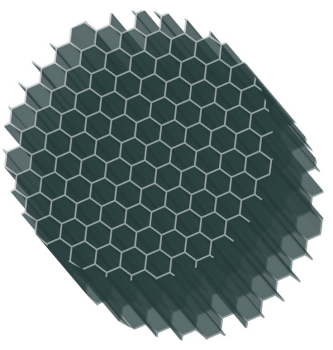

(b)

Figure 12: Honeycomb insert configuration for HTE in LP. (a). thin tubes [86; (b). honeycomb matrix 72

The honeycomb concept consist in substituting the large piston column by many long and thin tubes, the liquid flowing through these tubes to compress air. The thin tubes could have a circular geometry (Fig. 12a), or as hexagonal cells stacked in layers (Fig. 12b). The main advantages of this concept are the easy implementation of the inserts which gives a higher power density and an increased $L / D$ in each cell which enhances the heat transfer.

.

Zhang et al. [86, 72] numerically studied a LP compressor inserted with honeycomb geometry by CFD approach. Each tube channel had a $L / D$ ratio of 100. The liquid (moving boundary assumed as water) had a constant velocity and the walls had a constant temperature. In their study a transient $R e_{D h}$ number ranging from 130 to 1300 has been calculated based on the diameter (of 
1 the largest cylinder), the mean flow velocity, and a transient density. Moreover,

2 a $N u$-Re correlation was proposed for predicting the heat transfer based on the 3 local Darcian velocity $R e_{l c}$, where $l_{c}$ is the characteristic length [87:

$$
N u=2 f_{r}\left(\frac{l_{c}}{L_{d}} R e_{l c} P r\right)^{1 / 2}
$$

Where $f_{r}$ is the friction factor defined as Eq. 34 :

$$
f_{r}=\frac{0.564}{\left[1+\left(0.664 P r^{1 / 6}\right)^{9 / 2}\right]^{2 / 9}}
$$

Zhang et al. [72 has compared two concepts, a honeycomb insert and a porous media interrupted-plate heat exchanger, on the efficiency improvement of LP. The impacts of different parameters (material, length scale of the plate elements, specific surface area and porosity) on the temperature evolution were studied. A honeycomb insert with higher power density showed better air temperature abatement, and thus better efficiency. Nevertheless, the difference of $\eta_{c}$ among all tested configurations was below $4 \%$ (between $60 \%$ and $64 \%$ ).

In summary, the honeycomb concept with mini-tubes insert can take the maximum benefit from slow compression/expansion using a LP. They are easy to implement, but more investigations are still required to further investigate the effect of the materials and the $\mathrm{CR}$ on the heat transfer. Studies on the expansion will also help the application of this HTE concept.

\subsection{Hollow spheres}

The hollow sphere concept consists in adding a layer of floating spheres at the gas-liquid interface, which absorb the heat from the gas and transfer it to water. These hollow spheres move along with the interface during the compression or expansion. In this way, the overall heat transfer rate would be increased without adding much the compression work.

A numerical and experimental study has been conducted by Ramakrishnan et al. 88] on the effects of inserting hollow spheres (Fig. 13). An analytical 


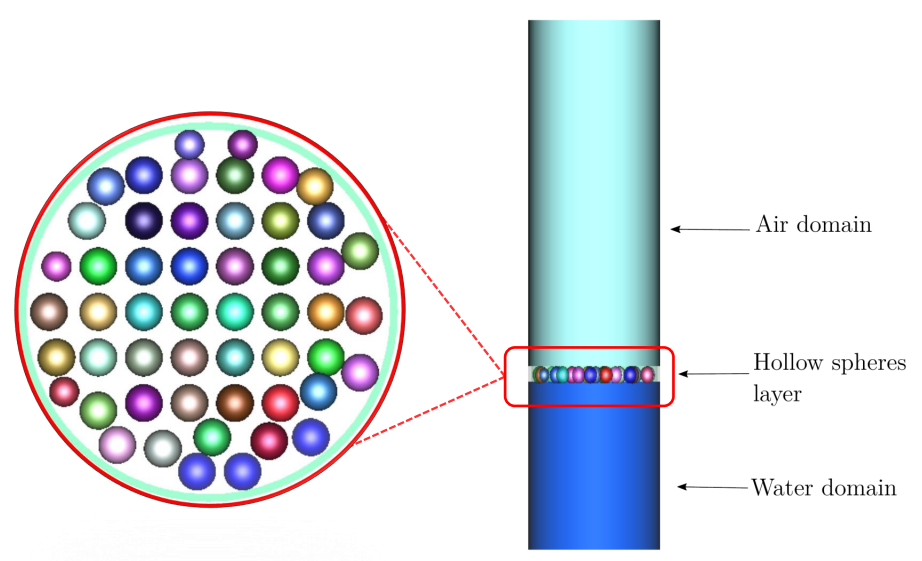

Figure 13: Hollow spheres concept for LP. Full LP domain ans Hollow spheres layer at the water/air interface

1 model has been developed for the compression, by assuming the temperature-

2 dependent physical properties of air. The viscosity has been calculated by using 3 the Sutherland formula:

$$
\mu(T)=\mu_{0}\left(\frac{T}{T_{0}}\right)^{1.5}\left(\frac{T_{0}+110.4}{T+110.4}\right)
$$

${ }_{5}$ where $\mu_{0}$ is the viscosity at $T_{0}=273 \mathrm{~K}$. An average $N u$ correlation for free 6 convection was chosen from the literature [88]:

7

$$
\begin{gathered}
\overline{N u_{D}}=2+\frac{0.589 R a_{D}^{0.25}}{\left[1+\left(\frac{0.469}{P r}\right)^{9 / 16}\right]^{4 / 9}} \\
R a=\frac{g \rho^{2} c}{T \lambda \mu}\left(T-T_{W}\right) D^{3}
\end{gathered}
$$

9 where $R a$ is the Rayleigh number, $D$ the diameter of the spheres, and $c$ the specific heat of air.

$$
c(T)=1002.5+275 \times 10^{-5}(T-200)^{2}
$$

The thermal conductivity of air $\lambda$ is calculated by:

13

$$
\lambda(T)=0.02624\left(\frac{T}{300}\right)^{0.8646}
$$



compression with hollow spheres insert.

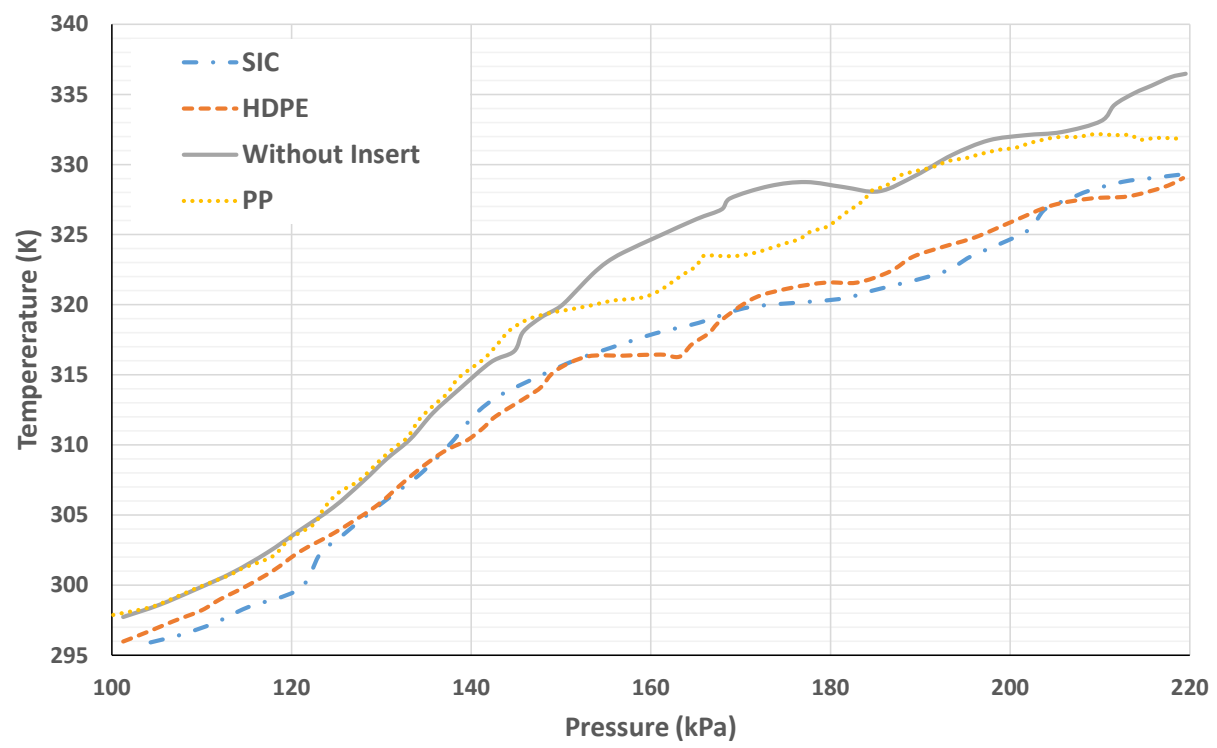

Figure 14: Experimental results on the effect of hollow spheres with different materials and sizes for $\mathrm{CR}=2$. Adapted from 88 results showed clearly the effect of the material of the spheres on the temperature abatement compared to the base case. HDPE (High-Density Polyethylene) and SiC (Silicon Carbide) showed better performance than PP (Polypropylene) (Fig. 14). Moreover, the smaller spheres diameter $(D=6.5 \mathrm{~mm})$ showed better $\eta_{c}$ than the larger one $(D=9 \mathrm{~mm})$ because of the higher total heat transfer surface area. A maximum temperature abatement of $32 \mathrm{~K}$ could be achieved by a fast

Although the study was limited to a small CR and a limited range of spheres' diameter/material, this concept has showed its effectiveness and easy implementation. Yet, more investigations are still needed to further test this concept under high pressures, high $\mathrm{CR}$ and high flow rates conditions.

Many influencing parameters were tested including the spheres diameter, the stroke time, the CR and the sphere's material (for the experimental part). The 


\subsection{Aqueous foam}

This concept consists in generating foam (with water additives) from the bottom of the piston which rises to the liquid/gas interface and increases the heat transfer surface between the liquid column and the compressed gas. This novel technique has been proposed and patented by SustainX [89] and studied experimentally by Patil \& Ro [90] for temperature abatement in a LP compressor. Compared to the droplet spray, the mixture of air and water as a homogeneous foam had several advantages, including the higher contacting surface area which can be maintained during the entire compression or expansion stroke. With the use of aqueous foam, it has been observed that the rise of air temperature could be reduced especially in the end of the compression process with higher temperature gradients, i.e., about 7 to $20 \mathrm{~K}$ at a $\mathrm{CR}=2.5$. This leaded to a $\eta_{c}$ increase of $4-8 \%$ to $86 \%$ of isothermal $\eta_{c}$. Moreover, the use of several foam generators (up to 4) could further increase the $\eta_{c}$ up to $90 \%$. The operating principle and the influence of the aqueous foam on the gas flow dynamics are illustrated in Fig. 15.

Patil \& Ro 90] used Skelland correlation (Eq. 40) 91] and Attia correlation (Eq. 41) 92 to model the heat transfer with aqueous foam in the LP. Nevertheless, none of them could give appropriate results due to the complexity of the physical phenomenon and the geometry.

$$
\begin{gathered}
N u_{x}=1.41\left(\frac{3 k+1}{4 k}\right)^{1 / 3}\left(\frac{D_{h} \operatorname{RePr} r}{x}\right)^{1 / 3} \text { and } \\
N u_{\infty}=\frac{8(5 k+1)(3 k+1)}{31 k^{2}+12 k+1}
\end{gathered}
$$

where $N u_{x}$ and $N u_{\infty}$ are the Nusselt number in the entry region and in thermally fully developed region, respectively. $k$ is the flow behavior index and $x$ is the length from the entrance.

$$
N u_{f o, x}=a C(\chi)^{-\frac{1}{6}}\left(C a_{f o}\right)^{\frac{1}{8}}\left(\frac{3 k+1}{4 k}\right)^{1 / 3}\left(\frac{D_{h} R e_{f o} P r_{f o}}{x}\right)^{1 / 3}
$$

where $\mathrm{a}$ is a constant to be determined from experimental data, $C(\chi)$ is an empirical function dependent on surfactant mass fraction $\xi$ in weight percentage and $C a_{f o}$ is the capillary number. The subscript fo denotes the foam. 


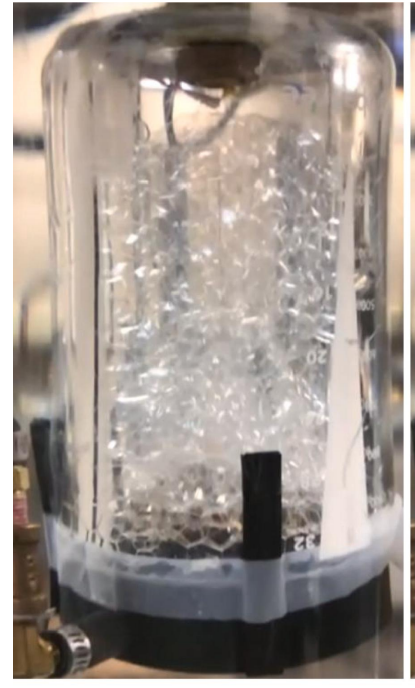

(a) At time $=0 \mathrm{~s}$

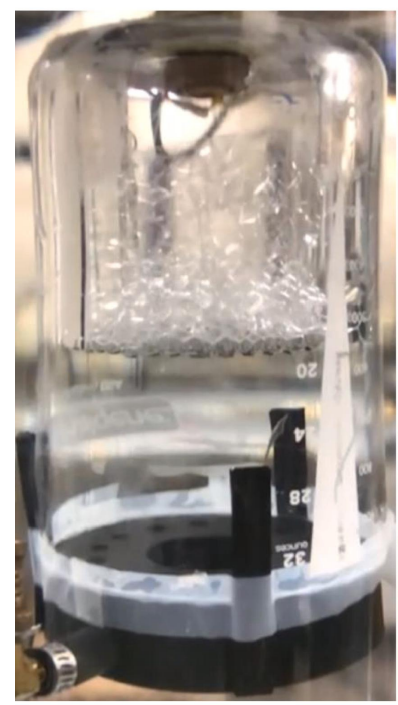

(d) At time $=2.7$

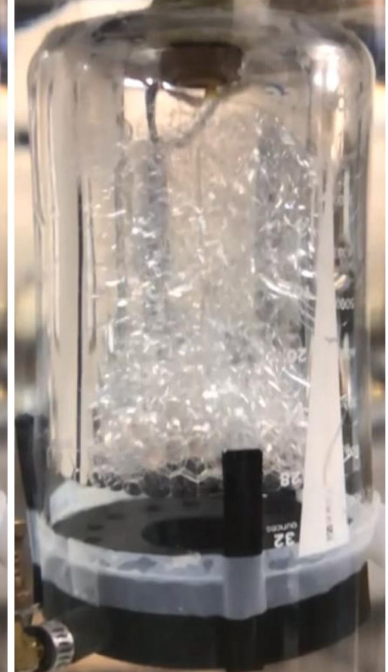

(b) At time $=0.9 \mathrm{~s}$

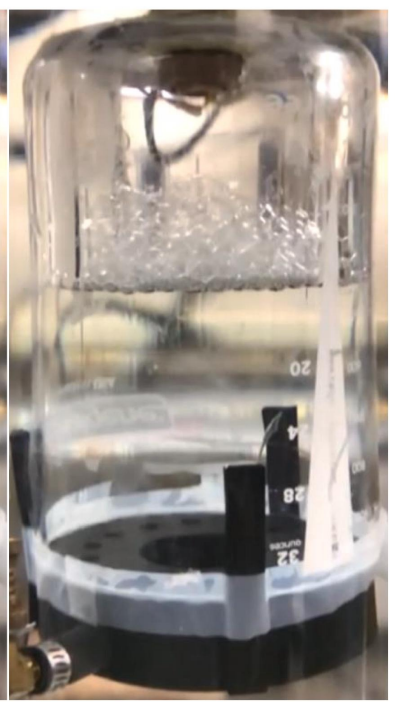

(e) At time $=3.6 \mathrm{~s}$

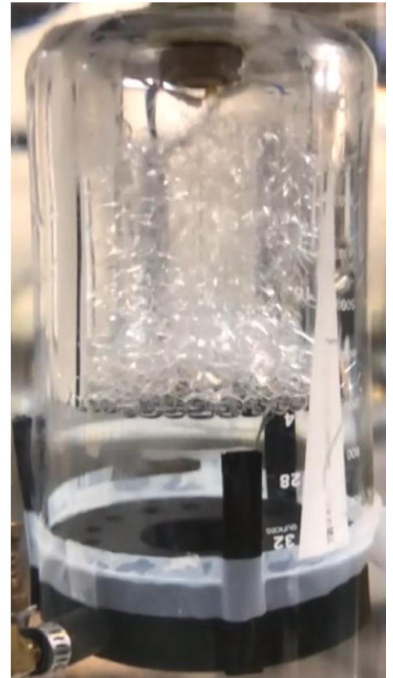

(c) At time $=1.8 \mathrm{~s}$

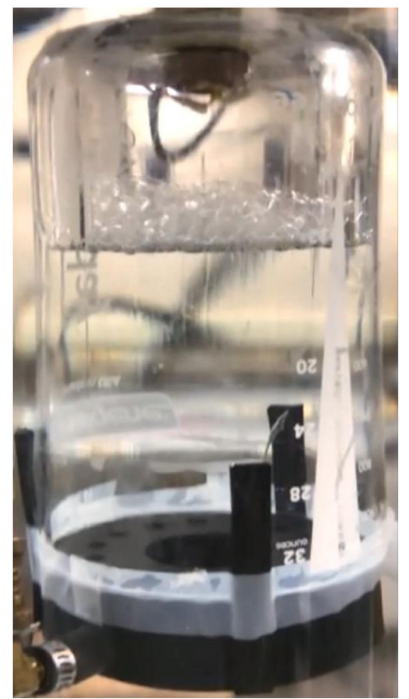

(f) At time $=4.37 \mathrm{~s}$

Figure 15: Aqueous foam bubble dynamics during the compression process 90]

The presence of foams in the gas domain inside the LP shows relatively 2 high heat transfer rate with a low mass flow rate. Therefore, the ratio of heat 3 transfer to coolant density is higher for foams. However, the accumulation of 4 residual foams after a few cycles could change the heat transfer characteristics 
1 and flow dynamics inside the LP and could lead to the corrosion in some parts

2 of the system. Effects of cyclic operation and variability of foams geometries have to be further studied so as to obtain more experimental feedback. Better scalability of the foam-based HTE could be ensured by further studies focusing on the use of microfoams, controlled macrofoams generation and under higher CR operations.

\subsection{Wire mesh}

Metal wire meshes can also be installed in the piston column in contact with both the gas and the liquid to enhance the heat transfer (Fig. 16a). For cylindrical column, an Archimedean spiral form could be used, facilitating the heat transfer in both the axial and radial directions (Fig. 16b). This concept could in fact be considered as a special case of porous media inserts.

Patil et al. 69] compared experimentally the effect of wire mesh on the pressure, the temperature and the efficiency of a LP compressor. Two types of wire mesh were tested, one in copper and another in aluminium (Fig.16)

(b). Their results showed a significant temperature abatement (about $25 \mathrm{~K}$ )

17 by adding the wire mesh. Meshes with larger wire size $(0.7112 \mathrm{~mm}$ or 3.5 18 wire $/ \mathrm{cm})$ were more efficient than that with smaller wire size $(0.4572 \mathrm{~mm}$ or 6 wire/cm). The compression speed also had an important influence on the final gas temperature. At medium velocity condition (4 s compression time), about $28 \mathrm{~K}$ temperature abatement could be achieved (Fig. 17). In general, the isothermal $\eta_{c}$ could be increased from $82-84 \%$ to $88-92 \%$ by using the wire mesh 69.

Only two materials (copper and aluminium) have been tested while more systematic investigations on many factors (e.g., wire diameters, mesh sizes, forms of the spiral and mesh position) are still needed, so as to achieve an optimal mesh design and to obtain the maximum efficiency. Also, the utility of metal wire meshes for high CR should be studied to ensure that the obtained efficiencies will also be maintained at high power levels. 


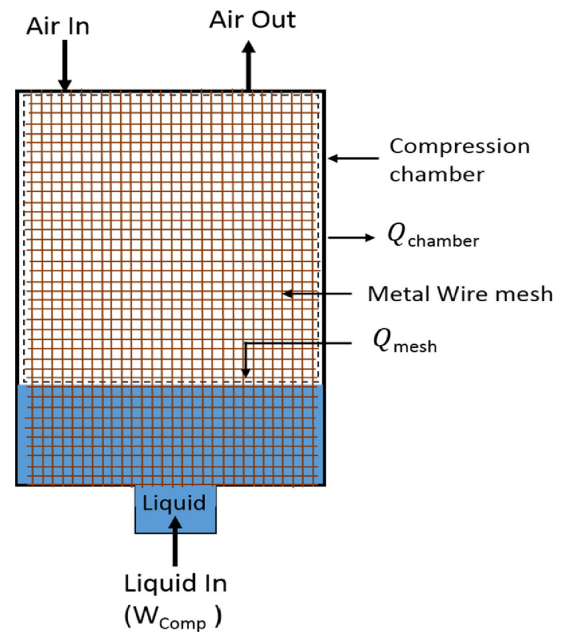

(a)

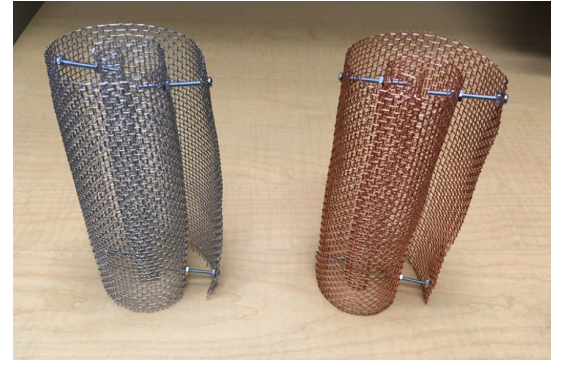

(b)

Figure 16: Wire mesh insert for LP 69. (a). schematic model; (b) photo of aluminum and copper wire mesh in Archimedean spiral form

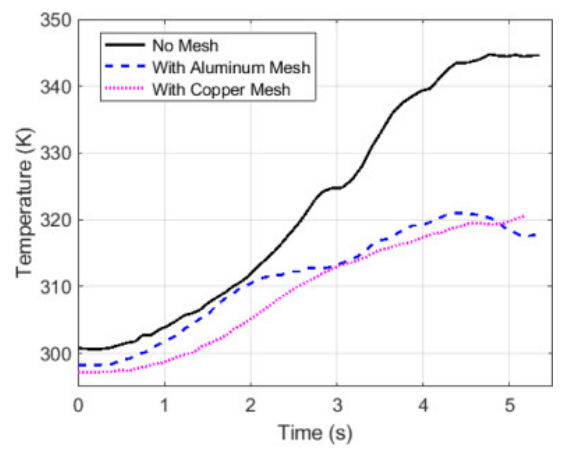

(a)

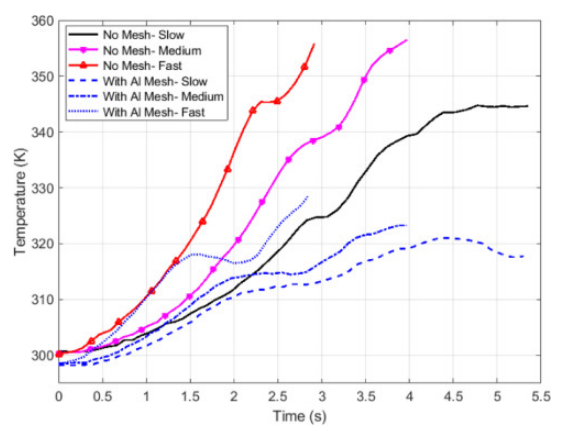

(b)

Figure 17: Wire mesh insert on the temperature evolution of LP 69. (a) Effect of mesh materials; (b) Effect of compression speed

\section{3.8. Optimal geometry of the piston column}

2 Another method to augment the compression/expansion efficiency is to op-

3 timize the shape of the piston column instead of the conventional cylinder one

4 with uniform cross-section area, shown as an example in Fig. 18. Zhang et al.

5 93. made a CFD-based design analysis for a LP compression chamber by vary-

${ }_{6}$ ing five geometrical parameters, including the inlet radius $R_{i}$, the maximum 
1 radius $R_{m}$, the top cap radius $R_{t}$, the location of the maximum radius $X_{m}$ with 2 respect to the inlet and the column length $L$ (Fig. 18). 16 designs were proposed and studied. Their numerical results showed that a longer column and a steeper change in cross-sectional radius would agitate the gas flow, enhancing thereby the heat transfer (Fig. 19). The optimal shape of the column as shown in Fig. $619 \mathrm{~b}(\mathrm{~b})$ had the following parameters: $P_{1}=\frac{L}{R_{m}}=8, \frac{R_{m}}{R_{i}}=6, P_{3}=\frac{X_{m}}{L}=0.5$, $7 \quad P_{4}=\frac{R_{m}}{R_{t}}=4$, improving the $\eta_{c}$ from $62 \%$ to $69 \%$.

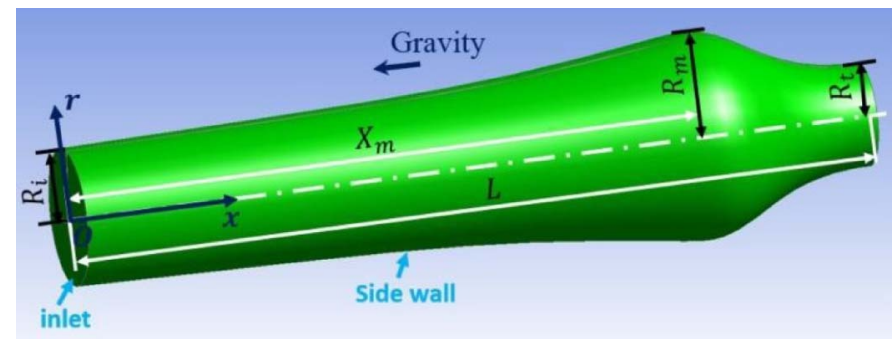

Figure 18: Schematic of LP chamber and shape parameters 93

Generally speaking, parametric study or topology optimization (geometry, piston velocity, materials, CR) are the best way to better understand and optimize the processes to help achieve the highest efficiencies. While it is costly to do such studies experimentally, numerical modeling based on CFD simulations could be more adapted and play an important role in the future. Once the optimal geometry of the column is determined, another problem is the fabrication difficulty and cost. Therefore, trade-off needs to be achieved for this concept for large-scale industrial application considering the computational cost, the efficiency improvement, the production cost, the material resistance and the installation in a real site.

\subsection{Summary of HTE concepts for LP}

Patil et al. 94 have compared several HTE concepts used in LP for CAES application. The comparison was done on the RTE value through a typical configuration of a global CAES system, composed of 4 LPs having a $L / D=10$ and a $C R=6$. The total stored energy was $2 \mathrm{MWh}$ [4]. By improving nothing 

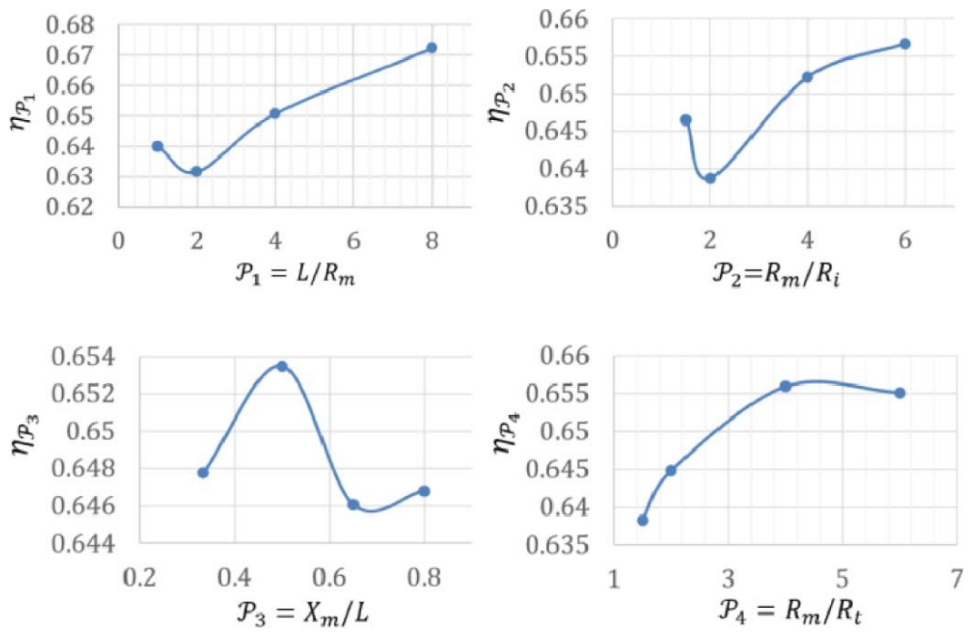

(a)
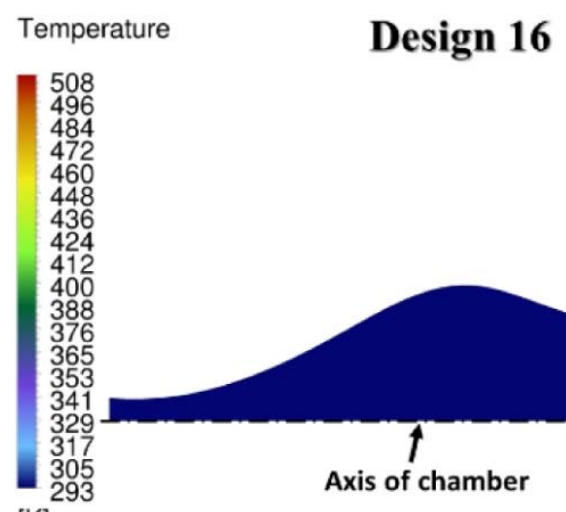

$[\mathrm{K}]$

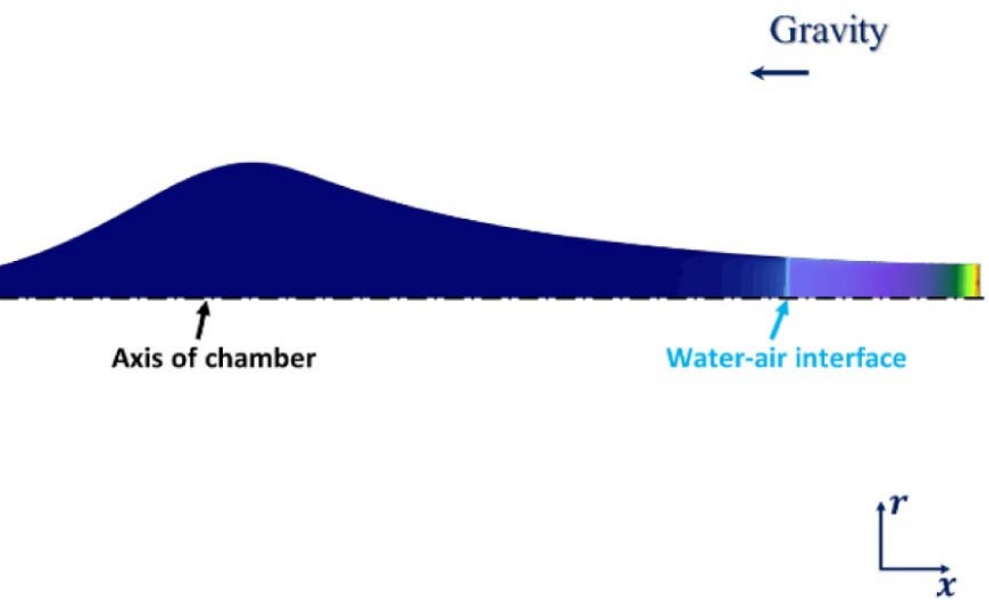

(b)

Figure 19: CFD-based shape optimization of the LP column 93. (a). Effect of single shape parameter on the efficiency improvement; (b). Optimal geometry of the LP column and the temperature field at the end of compression

1 more than the compression/expansion efficiency through thermal management, 2 the RTE of the CAES system could rise from $45 \%$ to up to $62 \%$ (Fig. 20).

3 The RTE improvement is different by using different HTE concepts, i.e., $5 \%$ 
1 by the optimal trajectory concept, $7 \%$ by hollow spheres insert, and more than $217 \%$ by spray cooling or by porous media inserts. Further improvement of 3 LP efficiency could be expected by combining two or several HTE methods, 4 stepping towards near-isothermal compression/expansion. For example, Ahn et 5 al. 95] combined wire mesh insert with the droplet spray but the effect of each 6 HTE measure could not be identified clearly. Further efforts should thereby 7 be devoted to the development and implementation of combined HTE methods.

8 Table 2 recapitulates the studies on the HTE technologies in LP with their main 9 results, conditions, advantages and shortcomings.

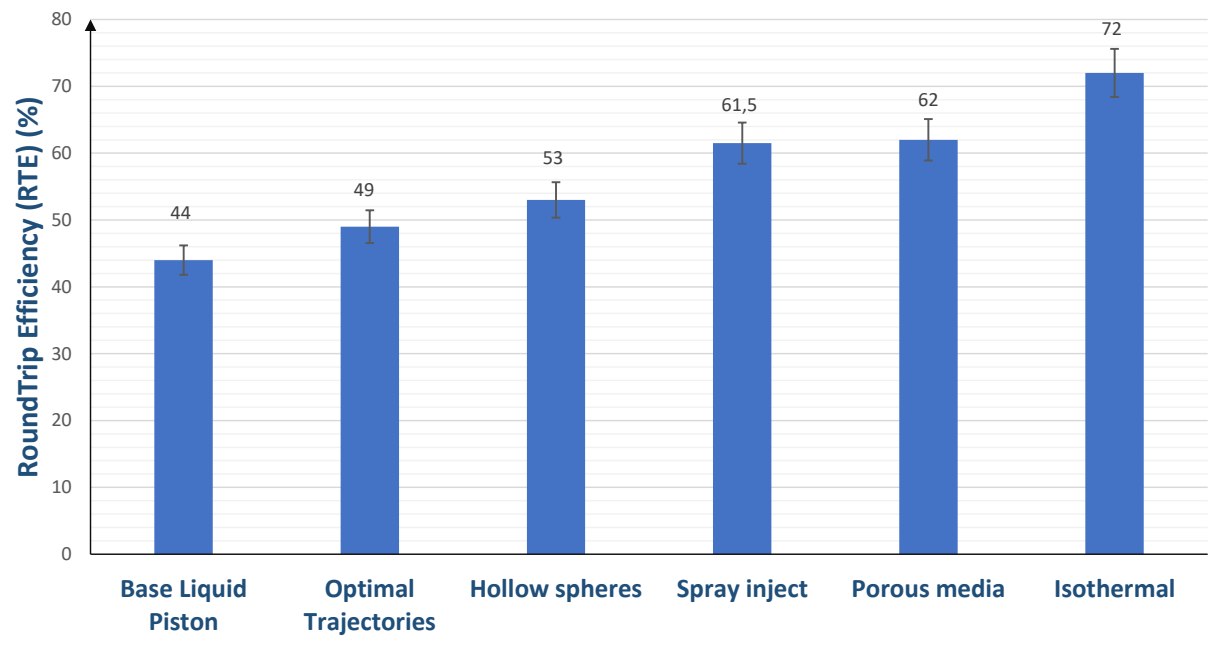

Figure 20: RTE efficiency improvement of a LP-based CAES system by implementing various HTE concepts (uncertainty bars represent 95\% confidence interval), adapted from 94 


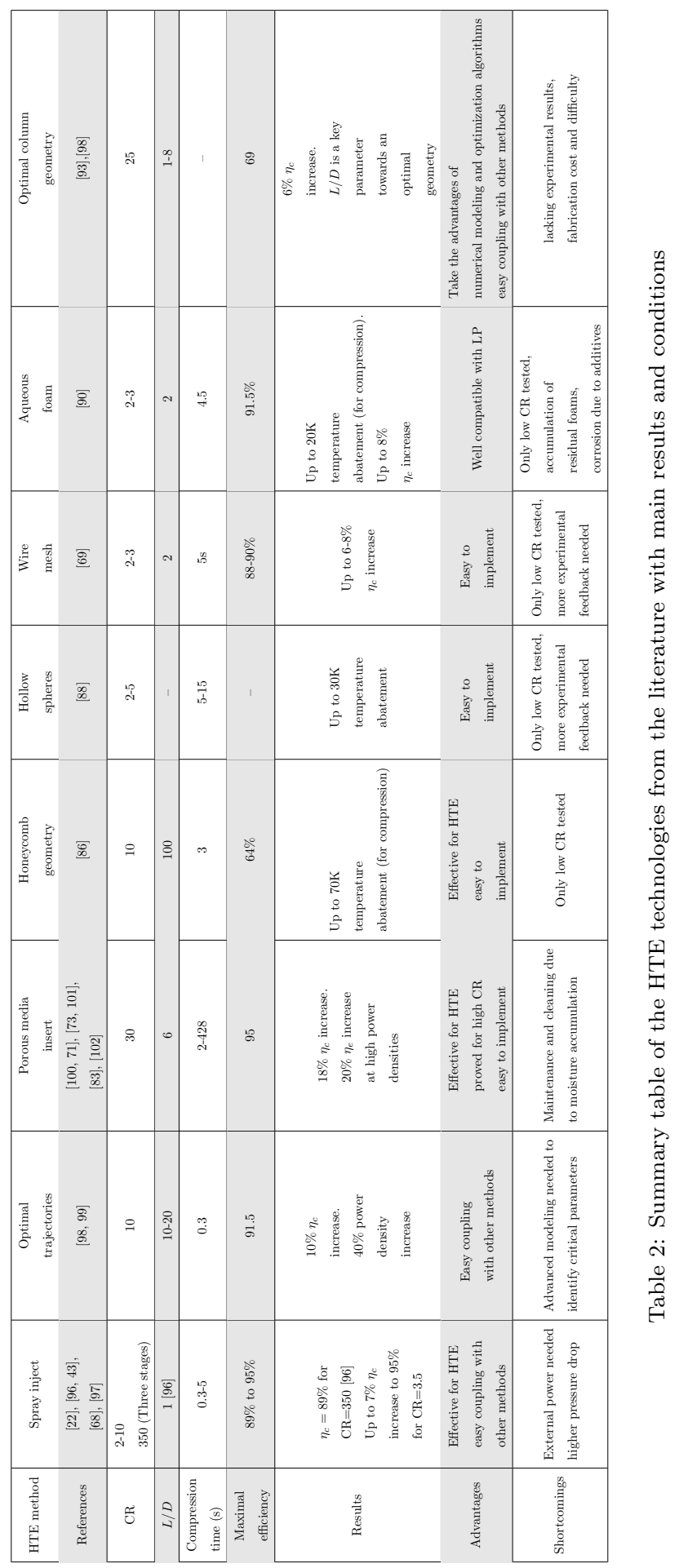


$1 \quad$ Nusselt number $N u$ has been shown to be the most used non-dimensional 2 number for estimating the heat transfer inside the LP during compression/expansion 3 processes. Different correlations have been proposed and used based on their 4 own applicable conditions. The generic form used to write $N u$ as a function of ${ }_{5} \operatorname{Re}$ and $\operatorname{Pr}$ numbers is defined in Eq. 20 and summarized in Table 3 together $6 \quad$ with other proposed correlations. 


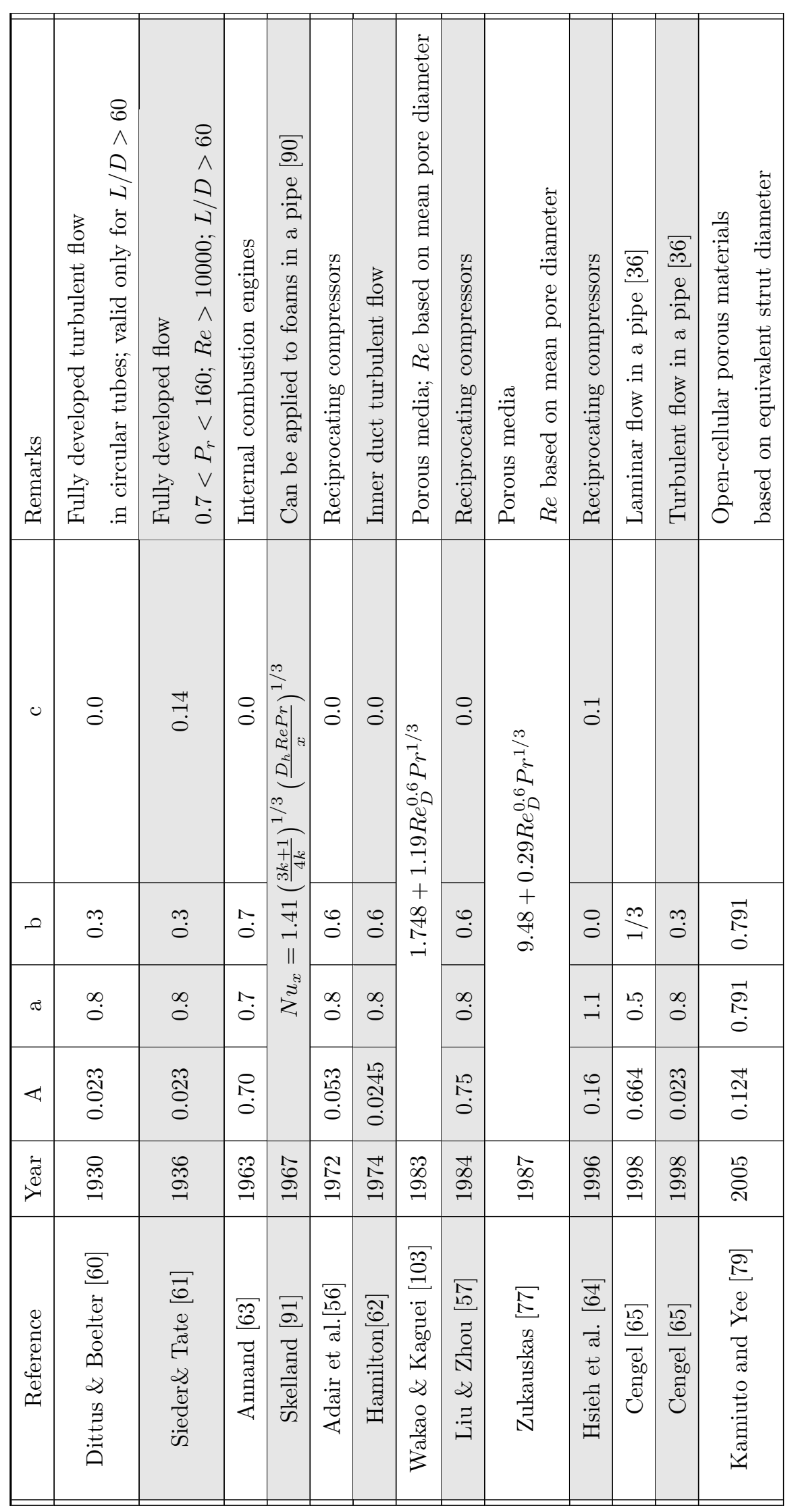




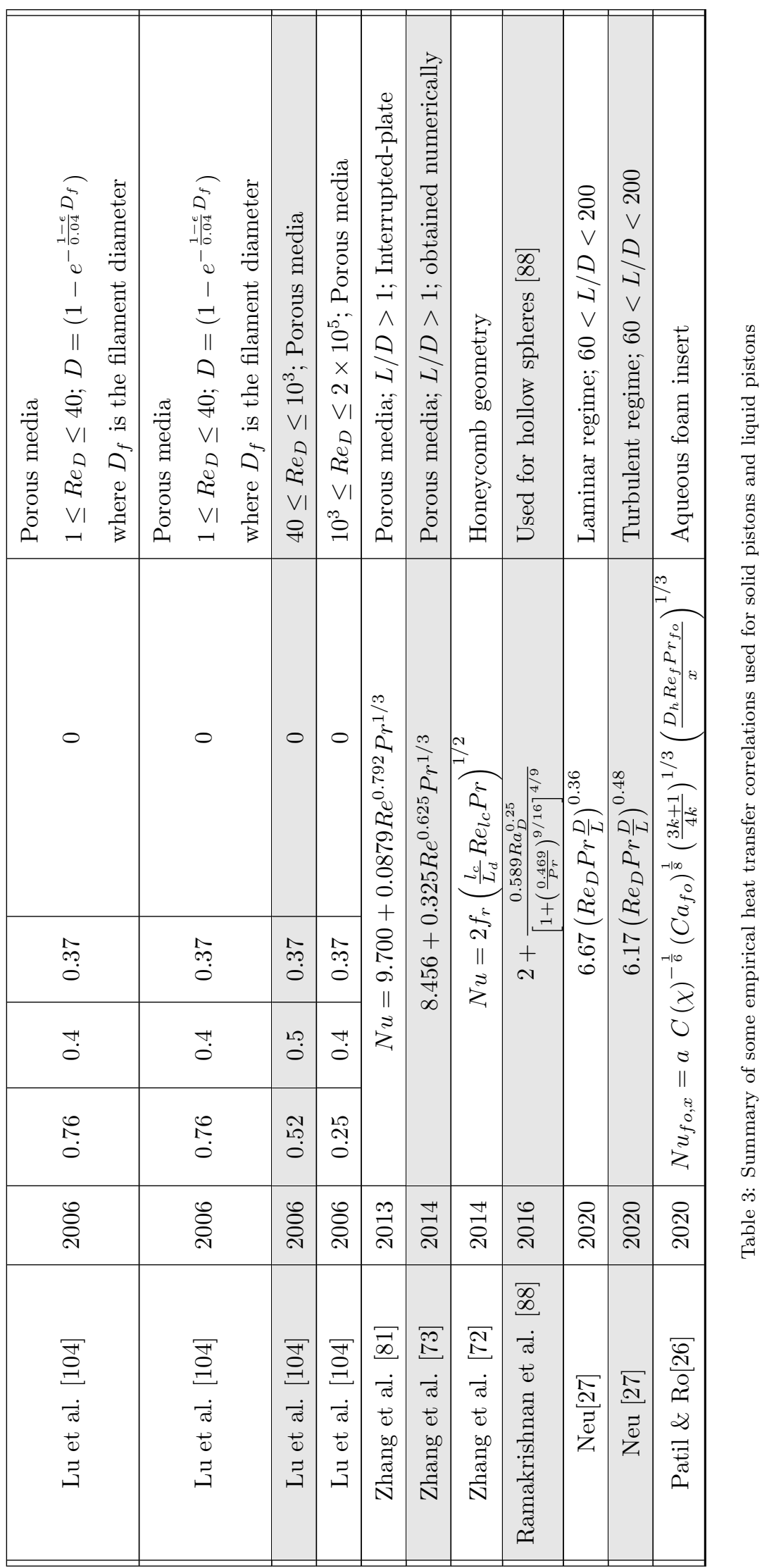


2

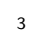

\section{Conclusion and perspectives}

This review paper is dedicated to gather and survey the advances of the LP technology for CAES. The basic principles, the thermodynamic background, the flow and heat transfer characteristics related to LP are presented in detail. Especially the technological state-of-the-art on the HTE concepts implemented in LP has been surveyed, aiming at approaching the isothermal compression/expansion. The main findings may be summarized as follows.

- Compared to solid piston, LP can allow high $L / D$ geometry and a flexible compression/expansion speed. Moreover, it is a promising way to achieve a near-isothermal process, which will have a bright foreground for I-CAES application.

- The fluid flow and heat transfer inside the LP during the compression or expansion operation are rather complex and difficult to characterize, especially for the transition and turbulent regimes.

- Many $\mathrm{Nu}$-Re correlations were employed to predict the heat transfer of the compression/expansion processes inside the LP, as summarized in Table 3. Almost all of them are based on the average value of $N u$ number or convective heat transfer coefficient.

- Different concepts were proposed to enhance the heat transfer in the LP, including liquid spray, wire mesh, porous media, optimal trajectory, hollow spheres and optimal geometry of the piston column. By using these HTE techniques the compression/expansion efficiency of the LP could be significantly improved up to $10 \%$, leading to the RTE increase of the CAES system. Each HTE concept has their own advantages and short comings while the combination of two or several concepts seems more promising. By implementing the proper HTE technique, the LP in a CAES system can achieve a $95 \%$ compression/expansion efficiency. 
Some scientific and technological barriers remain to be overcome for the widespread industrial application of LP, which are also the key issues and challenges of the current research and development:

- Fine models that describe the evolution of the flow \& heat transfer inside a LP during compression/expansion processes are still lacking. Therefore, systematic experimental and numerical studies are especially needed on the local coupled fluid flow and heat transfer behaviors, for better characterization, understanding and mastering the transient gas-liquid two phase flow transport phenomena.

- Critical geometric and operational parameters (flow rate, $\mathrm{CR}$, compression time, geometry, energy density, etc.) and the suitable combinations of them remain to be identified. This requires the development and application of advanced modeling and optimizing algorithms and experimental verification.

- Most of the LP studies are still on the laboratory scale with small LP dimensions and small $\mathrm{CR}$ values. The field testing at pilot or industrial scale with realistic $\mathrm{CR}$ are still rare but fully necessary for the possible application of LP in CAES systems.

- Further investigations on the new or combined HTE concepts, their testing and validation at pilot-scale prototypes are still required.

- Finally, studies are still required on full cyclic compression/expansion cycles considering all the auxiliary components (pumps, valves, etc.). Detailed thermodynamic and techno-economic analyses can also help determine the optimal operation conditions and adapted control strategies especially at pilot or industrial level.

\section{Acknowledgement}

This work is supported by the French Association Nationale Recherche Technologie (ANRT) under CIFRE program No. 2017/1100. 


\section{References}

2 [ [1] EIA, EIA projects nearly 50\% increase in world energy usage by 2050, led by growth in Asia - Today in Energy -, Tech. rep., Energy Information Administration (2019).

URL https://www .eia.gov/todayinenergy/detail.php?id=41433

[2] IEA, OECD, Global Energy Review 2019, OECD, 2020. doi:10.1787/ 90c8c125-en

URL https : //www . iea.org/reports/global-energy-review-2019

[3] United Nations, The Paris Agreement, Tech. rep., United Nations (2017). URL https://unfccc.int/process-and-meetings/the-paris-agre ement/the-paris-agreement

[4] Q. Zhou, D. Du, C. Lu, Q. He, W. Liu, A review of thermal energy storage in compressed air energy storage system, Energy 188 (2019) 115993. doi: $10.1016 / \mathrm{j} \cdot$ energy $\cdot 2019.115993$

[5] X. Luo, J. Wang, M. Dooner, J. Clarke, Overview of current development in electrical energy storage technologies and the application potential in power system operation, Applied Energy 137 (2015) 511-536. doi:10.1 016/j.apenergy.2014.09.081.

[6] U. Pelay, L. Luo, Y. Fan, D. Stitou, M. Rood, Thermal energy storage systems for concentrated solar power plants, Renewable and Sustainable Energy Reviews 79 (2017) 82-100. doi:10.1016/j.rser.2017.03.139.

[7] U. Pelay, L. Luo, Y. Fan, D. Stitou, C. Castelain, Integration of a thermochemical energy storage system in a Rankine cycle driven by concentrating solar power: Energy and exergy analyses, Energy 167 (2019) 498-510. doi:10.1016/j.energy.2018.10.163.

[8] U. Pelay, L. Luo, Y. Fan, D. Stitou, Dynamic modeling and simulation of a concentrating solar power plant integrated with a thermochemical 
energy storage system, Journal of Energy Storage 28 (2020) 101164. doi: $10.1016 / j$. est. 2019.101164 .

[9] K. E. N'Tsoukpoe, H. Liu, N. Le Pierrès, L. Luo, A review on long-term sorption solar energy storage, Renewable and Sustainable Energy Reviews 13 (9) (2009) 2385-2396. doi:https://doi.org/10.1016/j.rser.200 9.05 .008

[10] T. Guewouo, L. Luo, D. Tarlet, M. Tazerout, Identification of Optimal Parameters for a Small-Scale Compressed-Air Energy Storage System Using Real Coded Genetic Algorithm, Energies 12 (3) (2019) 377. doi:10.3390/en12030377

[11] G. Venkataramani, P. Parankusam, V. Ramalingam, J. Wang, A review on compressed air energy storage - A pathway for smart grid and polygeneration, Renewable and Sustainable Energy Reviews 62 (2016) 895-907. doi:10.1016/j.rser.2016.05.002.

[12] M. Budt, D. Wolf, R. Span, J. Yan, A review on compressed air energy storage: Basic principles, past milestones and recent developments, Applied Energy 170 (2016) 250-268. doi:10.1016/j.apenergy.2016.02.1 08 .

[13] H. Chen, T. N. Cong, W. Yang, C. Tan, Y. Li, Y. Ding, Progress in electrical energy storage system: A critical review, Progress in Natural Science 19 (3) (2009) 291-312. doi:10.1016/j.pnsc.2008.07.014.

[14] T. M. Letcher, Storing electrical energy, in: Managing Global Warming: An Interface of Technology and Human Issues, Elsevier, 2018, pp. 365377. doi:10.1016/B978-0-12-814104-5.00011-9.

[15] IEA, Will pumped storage hydropower expand more quickly than stationary battery storage? Analysis (2019). URL https://www.iea.org/articles/will-pumped-storage-hydro power-expand-more-quickly-than-stationary-battery-storage 
[16] C. Haisheng, Z. Xinjing, L. Jinchao, T. Chunqing, Compressed air energy storage, in: Ahmed Faheem Zobaa (Ed.), Energy Storage - Technologies and Applications, CRC Press, 2013, Ch. Compressed, pp. 111-152. doi: $10.5772 / 52221$.

[17] L. Li, W. Liang, H. Lian, J. Yang, M. Dusseault, Compressed air energy storage: Characteristics, basic principles, and geological considerations, Geo-Energy Research 2 (2) (2018) 135-147. doi:10.26804/ager.2018.0 2.03

[18] A. G. Olabi, T. Wilberforce, M. Ramadan, M. A. Abdelkareem, A. H. Alami, Compressed air energy storage systems: Components and operating parameters - A review, Journal of Energy Storage 34 (2021) 102000. doi:10.1016/J.EST.2020.102000

[19] C. R. Matos, J. F. Carneiro, P. P. Silva, Overview of Large-Scale Underground Energy Storage Technologies for Integration of Renewable Energies and Criteria for Reservoir Identification, Journal of Energy Storage 21 (2019) 241-258. doi:10.1016/J.EST .2018.11.023

[20] W. He, J. Wang, Optimal selection of air expansion machine in Compressed Air Energy Storage: A review, Renewable and Sustainable Energy Reviews 87 (2018) 77-95. doi:10.1016/j.rser.2018.01.013.

[21] M. Raju, S. Kumar Khaitan, Modeling and simulation of compressed air storage in caverns: A case study of the Huntorf plant, Applied Energy 89 (1) (2012) 474-481. doi:10.1016/j .apenergy.2011.08.019.

[22] A. Odukomaiya, A. Abu-Heiba, K. R. Gluesenkamp, O. Abdelaziz, R. K. Jackson, C. Daniel, S. Graham, A. M. Momen, Thermal analysis of nearisothermal compressed gas energy storage system, Applied Energy 179 (2016) 948-960. doi:10.1016/j .apenergy .2016.07.059.

[23] A. Odukomaiya, E. Kokou, Z. Hussein, A. Abu-Heiba, S. Graham, A. M. 
Momen, Near-isothermal-isobaric compressed gas energy storage, Journal of Energy Storage 12 (2017) 276-287. doi:10.1016/j.est.2017.05.014

[24] J.-k. Park, P. I. Ro, X. He, A. P. Mazzoleni, Analysis and Proof-ofConcept Experiment of Liquid-Piston Compression for Ocean Compressed Air Energy Storage (Ocaes) System, Marine Energy Technology Sympo$\operatorname{sium}(2014)$.

[25] V. C. Patil, P. I. Ro, Modeling of liquid-piston based design for isothermal ocean compressed air energy storage system, Journal of Energy Storage 31 (2020) 101449. doi:10.1016/j.est.2020.101449.

[26] V. C. Patil, P. I. Ro, Design of Ocean Compressed Air Energy Storage System, in: 2019 IEEE International Underwater Technology Symposium, UT 2019 - Proceedings, Institute of Electrical and Electronics Engineers Inc., 2019, pp. 1-8. doi:10.1109/UT.2019.8734418.

[27] T. Neu, C. Solliec, B. dos Santos Piccoli, Experimental study of convective heat transfer during liquid piston compressions applied to near isothermal underwater compressed-air energy storage, Journal of Energy Storage 32 (2020) 101827. doi:10.1016/j.est.2020.101827.

[28] O. Maisonnave, L. Moreau, R. Aubrée, M. F. Benkhoris, T. Neu, D. Guyomarc'h, Optimal energy management of an underwater compressed air energy storage station using pumping systems, Energy Conversion and Management 165 (2018) 771-782. doi:10.1016/j.enconman.2018.04.0 07.

[29] Segula Technologies, REMORA — Segula Technologies (2020).

a URL https://www.segulatechnologies.com/fr/innovation/projet/ remora/

[ [30] RWE Corporation, ADELE to store electricity efficiently, safely and in large quantities (2013). 

$4 \quad$ Now $(2012)$. .102532

URL http: //www.rwe.com/web/cms/en/113648/rwe/press-news/pre ss-release $/$ ?pmid $=4004404$

31] LightSail, LightSail Energy. Regenerative Air Energy Storage. — Watt

URL https://wattnow.org/2012/02/lightsail-energy-regenerativ e-air-energy-storage/

[32] G. compression, General Compression and SustainX merges (2015). URL https://energystorageforum . com/news/nrstor-advances-caes -ontario-general-compression-sustainx-merges

[33] A. Odukomaiya, A. Abu-Heiba, S. Graham, A. M. Momen, Experimental and analytical evaluation of a hydro-pneumatic compressed-air GroundLevel Integrated Diverse Energy Storage (GLIDES) system, Applied Energy 221 (2018) 75-85. doi:10.1016/j.apenergy .2018.03.110.

[34] D. Buhagiar, T. Sant, Modelling of a novel hydro-pneumatic accumulator for large-scale offshore energy storage applications, Journal of Energy Storage 14 (2017) 283-294. doi:10.1016/j.est.2017.05.005.

[35] EnairysPowertech, Enairys - Clean energy storage \& management solutions based on Compressed air (2021). URL https://www.enairys.com/

[36] J. D. Van de Ven, P. Y. Li, Liquid piston gas compression, Applied Energy 86 (10) (2009) 2183-2191. doi:10.1016/j.apenergy.2008.12.001

[37] V. C. Patil, P. Acharya, P. I. Ro, Experimental investigation of heat transfer in liquid piston compressor, Applied Thermal Engineering 146 (2019) 169-179. doi:10.1016/j.applthermaleng.2018.09.121

[38] T. Neu, A. Subrenat, Experimental investigation of internal air flow during slow piston compression into isothermal compressed air energy storage, Journal of Energy Storage 38 (2021) 102532. doi:10.1016/j.est.2021 
[39] Digital Science, Dimensions (2018). URL https://app.dimensions.ai

[40] H. A. Humphrey, An Internal-Combustion Pump, and other Applications of a New Principle, Proceedings of the Institution of Mechanical Engineers 77 (1) (1909) 1075-1200. doi:10.1243/pime_proc_1909_077_019_02.

[41] J. Gerstmann, W. S. Hill, Isothermalization of Stirling Heat-Actuated Heat Pumps Using Liquid Pistons., Proceedings of the Intersociety Energy Conversion Engineering Conference 21st (1) (1986) 377-382.

[42] C. West, Liquid piston stirling engines, Springer-Verlag, 1985. doi:10.1 007/978-3-642-82526-2_10.

[43] C. Qin, E. Loth, Liquid piston compression efficiency with droplet heat transfer, Applied Energy 114 (2014) 539-550. doi:10.1016/j .apenergy .2013 .10 .005 .

[44] V. C. Patil, P. I. Ro, R. Kishore Ranganath, End-to-end efficiency of liquid piston based ocean compressed air energy storage, in: OCEANS 2016 MTS/IEEE Monterey, OCE 2016, Institute of Electrical and Electronics Engineers Inc., 2016, pp. 1-5. doi:10.1109/OCEANS.2016.7761399.

[45] M. Schober, M. Deichsel, E. Schlücker, CFD-simulation and experimental validation of heat transfer in liquid piston compressors, in: 12th International Conference on Heat Transfer, Fluid Mechanics and Thermodynamics, HEFAT, 2016, pp. 511-516.

[46] Numerical Modeling of Liquid Piston Gas Compression, Vol. Volume 9: Heat Transfer, Fluid Flows, and Thermal Systems, Parts A, B and C of ASME International Mechanical Engineering Congress and Exposition. doi:10.1115/IMECE2009-10621.

[47] S. Lemofouet, Investigation and optimisation of hybrid electricity storage systems based on compressed air and supercapacitors, Ph.D. thesis, EPFL (2006). doi:10.5075/EPFL-THESIS-3628. 
[48] S. Lemofouet, A. Rufer, A hybrid energy storage system based on compressed air and supercapacitors with maximum efficiency point tracking (MEPT), IEEE Transactions on Industrial Electronics 53 (4) (2006) 11051115. doi:10.1109/TIE.2006.878323

[49] G. Dib, P. Haberschill, R. Rullière, R. Revellin, Thermodynamic investigation of quasi-isothermal air compression/expansion for energy storage, Energy Conversion and Management 235 (2021) 114027. doi: $10.1016 / j$.enconman.2021.114027

[50] B. Yan, J. H. Wieberdink, F. A. Shirazi, P. Y. Li, T. W. Simon, J. D. Van de Ven, Experimental study of heat transfer enhancement in a liquid piston compressor/expander using porous media inserts, Applied Energy 154 (2015) 40-50. doi:10.1016/j.apenergy.2015.04.106

[51] V. C. Patil, P. I. Ro, Energy and Exergy Analysis of Ocean Compressed Air Energy Storage Concepts, in: Journal of Engineering (United States), Vol. 2018, 2018, pp. 1-14. doi:10.1155/2018/5254102.

[52] M. Mutlu, M. Kiliç, Effects of piston speed, compression ratio and cylinder geometry on system performance of a liquid piston, Thermal Science 20 (5) (2016) 1953-1961. doi:10.2298/TSCI140926146M.

[53] T. Neu, Etude expérimentale et modélisation de la compression quasi isotherme d'air pour le stockage d'énergie en mer, Ph.D. thesis, Ecole nationale supérieure Mines-Télécom Atlantique (jun 2017).

[54] E. M. Gouda, M. Benaouicha, T. Neu, Y. Fan, L. Luo, T. Neu, Méthode VOF pour la simulation numérique de l'écoulement de l'air comprimé et du transfert thermique associé dans un piston liquide, in: Congrès Français de Mécanique, Brest, France, 2019, p. 53. doi:https://cfm2019.scie ncesconf .org/244919.

[55] S. Langdon-Arms, M. Gschwendtner, M. Neumaier, Rayleigh-Taylor instability in oscillating liquid pistons, Proceedings of the Institution of 
Mechanical Engineers, Part C: Journal of Mechanical Engineering Science 233 (4) (2019) 1236-1245. doi:10.1177/0954406218768836.

[56] R. P. Adair, E. B. Quale, J. T. Pearson, Instantaneous Heat Transfer To the Cylinder Wall in Reciprocating Compressors, in: International Compressor Engineering Conference, School Of Mechanical Engineering, 1972, pp. 521-6.

[57] R. Liu, Z. Zhou, Heat Transfer Between Gas and Cylinder Wall of Refrigerating Reciprocating Compressor., Proceedings of the Purdue Compressor Technology Conference (1984) 110-115.

[58] M. Nikanjam, R. Greif, Heat transfer during piston compression, Journal of Heat Transfer 100 (3) (1978) 527-530. doi:10.1115/1.3450842.

[59] N. Arjomand Kermani, M. Rokni, Heat transfer analysis of liquid piston compressor for hydrogen applications, International Journal of Hydrogen Energy 40 (35) (2015) 11522-11529. doi:10.1016/j.ijhydene.2015.01 .098 .

[60] F. W. Dittus, L. M. Boelter, Heat transfer in automobile radiators of the tubular type, International Communications in Heat and Mass Transfer 12 (1) (1985) 3-22. doi:10.1016/0735-1933(85)90003-X.

[61] E. N. Sieder, G. E. Tate, Heat Transfer and Pressure Drop of Liquids in Tubes, Industrial and Engineering Chemistry 28 (12) (1936) 1429-1435. doi:10.1021/ie50324a027.

[62] J. Hamilton, Extensions of mathematical modeling of positive displacement type compressors, Purdue University School of Mechanical Engineering Ray W. Herrick Laboratories, West Lafayette IN, 1974.

[63] W. J. D. Annand, Heat Transfer in the Cylinders of Reciprocating Internal Combustion Engines, Proceedings of the Institution of Mechanical Engineers 177 (1) (2007) 973-996. doi:10.1243/pime_proc_1963_177_069_02. 
[64] W. H. Hsieh, T. T. Wu, Experimental investigation of heat transfer in a high-pressure reciprocating gas compressor, Experimental Thermal and Fluid Science 13 (1) (1996) 44-54. doi:10.1016/0894-1777(96)00013-1

[65] Y. Cengel, Heat Transfer, A Practical Approach, McGraw-Hill, Boston, 1998.

[66] W. Ranz, W. Marshall, Evaporation from drops: Part 2, Chemical Engineering Progress 48 (4) (1952) $173-180$.

[67] X. Zhang, Y. Xu, X. Zhou, Y. Zhang, W. Li, Z. Zuo, H. Guo, Y. Huang, H. Chen, Numerical Study of a Quasi-isothermal Expander by Spraying Water, Energy Procedia 142 (2017) 3388-3393. doi:10.1016/j.egypro .2017 .12 .475 .

[68] J. Guanwei, X. Weiqing, C. Maolin, S. Yan, Micron-sized water spraycooled quasi-isothermal compression for compressed air energy storage, Experimental Thermal and Fluid Science 96 (2018) 470-481. doi:10.101 6/j.expthermflusci.2018.03.032

[69] V. C. Patil, J. Liu, P. I. Ro, Efficiency improvement of liquid piston compressor using metal wire mesh for near-isothermal compressed air energy storage application, Journal of Energy Storage 28 (2020) 101226. doi:10.1016/j.est.2020.101226

[70] V. C. Patil, J. Liu, P. I. Ro, Efficiency Improvement of a Liquid Piston Compressor Using Metal Wire Mesh, in: ASME 2019 Power Conference, Vol. 2019-July, American Society of Mechanical Engineers, 2019, p. V001T12A009. doi:10.1115/POWER2019-1945.

[71] J. Wieberdink, P. Y. Li, T. W. Simon, J. D. Van de Ven, Effects of porous media insert on the efficiency and power density of a high pressure (210 bar) liquid piston air compressor/expander : An experimental study, Applied Energy 212 (2018) 1025-1037. doi:10.1016/j .apenergy . 2017. 12.093 . 
[72] C. Zhang, J. H. Wieberdink, T. W. Simon, P. Y. Li, J. D. Van de Ven,

E. Loth, Numerical analysis of heat exchangers used in a liquid piston compressor using a one-dimensional model with an embedded twodimensional submodel, in: ASME International Mechanical Engineering Congress and Exposition, Proceedings (IMECE), Vol. 8A, ASME, 2014, p. V08AT10A095. doi:10.1115/IMECE2014-38567.

[73] C. Zhang, B. Yan, J. H. Wieberdink, P. Y. Li, J. D. Van de Ven, E. Loth, T. W. Simon, Thermal analysis of a compressor for application to Compressed Air Energy Storage, Applied Thermal Engineering 73 (2) (2014) 1402-1411. doi:10.1016/j.applthermaleng.2014.08.014.

[74] C. Zhang, J. H. Wieberdink, F. A. Shirazi, B. Yan, T. W. Simon, P. Y. Li, Numerical investigation of metal-foam filled liquid piston compressor using a two-energy equation formulation based on experimentally validated models, in: ASME International Mechanical Engineering Congress and Exposition, Proceedings (IMECE), Vol. 8 B, ASME, 2013, p. V08BT09A045. doi:10.1115/IMECE2013-63854.

[75] N. Wakao, S. Kaguei, Heat and mass transfer in packed beds, AIChE Journal 29 (6) (1983) 1055-1055. doi:10.1002/aic.690290627.

[76] F. Kuwahara, M. Shirota, A. Nakayama, A numerical study of interfacial convective heat transfer coefficient in two-energy equation model for convection in porous media, International Journal of Heat and Mass Transfer 44 (6) (2001) 1153-1159. doi:10.1016/S0017-9310(00)00166-6.

[77] A. Zukauskas, Convective heat transfer in cross flow, in: S. Kakaç, R. K. Shah, W. Aung. (Eds.), Handbook of Single-Phase Convective Heat Transfer, John Wiley \& Sons, 1987, pp. 175-176.

[78] A. Nakayama, K. Ando, C. Yang, Y. Sano, F. Kuwahara, J. Liu, A study on interstitial heat transfer in consolidated and unconsolidated porous media, Heat and Mass Transfer/Waerme- und Stoffuebertragung 45 (11) (2009) 1365-1372. doi:10.1007/s00231-009-0513-x. 
[79] K. Kamiuto, S. S. Yee, Heat transfer correlations for open-cellular porous materials, International Communications in Heat and Mass Transfer 32 (7) (2005) 947-953. doi:10.1016/j.icheatmasstransfer.2004.10.027.

[80] X. Fu, R. Viskanta, J. P. Gore, Measurement and correlation of volumetric heat transfer coefficients of cellular ceramics, Experimental Thermal and Fluid Science 17 (4) (1998) 285-293. doi:10.1016/S0894-1777(98) 100 $02-\mathrm{X}$.

[81] C. Zhang, F. A. Shirazi, B. Yan, T. W. Simon, P. Y. Li, J. D. Van de Ven, Design of an interrupted-plate heat exchanger used in a liquid-piston compression chamber for compressed air energy storage, in: ASME 2013 Heat Transfer Summer Conf. Collocated with the ASME 2013 7th Int. Conf. on Energy Sustainability and the ASME 2013 11th Int. Conf. on Fuel Cell Science, Engineering and Technology, HT 2013, Vol. 2, ASME, 2013, p. V002T04A002. doi:10.1115/HT2013-17484

[82] T. Ren, W. Xu, M. Cai, X. Wang, M. Li, Experiments on air compression with an isothermal piston for energy storage, Energies 12 (19) (2019) 3730. doi:10.3390/en12193730

[83] S. Khaljani, Y. Mahmoudi, A. Murphy, J. Harrison, D. Surplus, M. Khaljani, A. Murphy, Y. Mahmoudi, J. Harrison, D. Surplus, Thermodynamic and heat transfer analysis of a Liquid Piston Gas Compressor (LPGC), in: International Conference on Innovative Applied Energy, Oxford, United Kingdom, 2019, p. 270.

[84] R. Boichot, Y. Fan, A genetic algorithm for topology optimization of area-to-point heat conduction problem, International Journal of Thermal Sciences 108 (2016) 209-217. doi:10.1016/J. I JTHERMALSCI.2016.05.0 15.

[85] M. Saadat, P. Y. Li, T. W. Simon, Optimal trajectories for a liquid piston compressor/expander in a Compressed Air Energy Storage 
system with consideration of heat transfer and friction, in: Proceedings of the American Control Conference, IEEE, 2012, pp. 1800-1805. doi:10.1109/acc.2012.6315616

[86] C. Zhang, M. Saadat, P. Y. Li, T. W. Simon, Heat transfer in a long, thin tube section of an air compressor: An empirical correlation from CFD and a thermodynamic modeling, in: ASME International Mechanical Engineering Congress and Exposition, Proceedings (IMECE), Vol. 7, 2012, pp. 1601-1607. doi:10.1115/IMECE2012-86673.

[87] G. P. Celata, B. Thonon, A. Bontemps, S. Kandlikar, Laminar Flow Friction and Heat Transfer in Non- Circular Ducts and Channels Part IIThermal Problem, Compact Heat Exchangers A Festschrift on the 60 th Birthday of Ramesh K . Shah (2002) 131-139.

[88] K. R. Ramakrishnan, P. I. Ro, V. C. Patil, Temperature abatement using hollow spheres in liquid piston compressor for Ocean Compressed Air Energy Storage system, in: OCEANS 2016 MTS/IEEE Monterey, OCE 2016, IEEE, 2016, pp. 1-5. doi:10.1109/OCEANS.2016.7761341.

[89] B. Bollinger, Demonstration of Isothermal Compressed Air Energy Storage to Support Renewable Energy Production, SustainX Smart Grid Program (2015) 1-49doi:10.2172/1178542.

[90] V. C. Patil, P. I. Ro, Experimental study of heat transfer enhancement in liquid piston compressor using aqueous foam, Applied Thermal Engineering 164 (jan 2020). doi:10.1016/j.applthermaleng.2019.114441.

[91] A. H. Skelland, Heat transfer in turbulent non-Newtonian flow, Journal of Engineering Physics 19 (3) (1970) 1059-1066. doi:10.1007/BF00826227.

[92] J. A. Attia, I. M. McKinley, D. Moreno-Magana, L. Pilon, Convective heat transfer in foams under laminar flow in pipes and tube bundles, International Journal of Heat and Mass Transfer 55 (25-26) (2012) 78237831. doi:10.1016/j.ijheatmasstransfer.2012.08.005. 
[93] C. Zhang, P. Y. Li, J. D. Van De Ven, T. W. Simon, Design analysis of a liquid-piston compression chamber with application to compressed air energy storage, Applied Thermal Engineering 101 (2016) 704-709. doi: 10.1016/j.applthermaleng. 2016.01.082

[94] V. C. Patil, R. R. Kishore, P. Ro, Efficiency Improvement Techniques For Liquid Piston based Ocean Compressed Air Energy Storage, TechConnect Briefs 2 (2017) (2017) 136-139.

[95] B. Ahn, P. I. Ro, V. C. Patil, Temperature Abatement using Spray Injection and Metal Wire Mesh in Liquid Piston Compressor for Ocean Compressed Air Energy Storage Application, Proceedings of the Annual Offshore Technology Conference 2020-May (may 2020). doi:10.4043/30 689-MS

[96] C. Qin, E. Loth, P. Y. Li, T. Simon, J. Van De Ven, Spray-cooling concept for wind-based compressed air energy storage, Journal of Renewable and Sustainable Energy 6 (4) (2014) 043125. doi:10.1063/1.4893434.

[97] V. C. Patil, P. Acharya, P. I. Ro, Experimental investigation of water spray injection in liquid piston for near-isothermal compression, Applied Energy 259 (2020) 114182. doi:10.1016/j.apenergy.2019.114182.

[98] M. Saadat, P. Y. Li, Combined Optimal Design and Control of a Near Isothermal Liquid Piston Air Compressor/Expander for a Compressed Air Energy Storage (CAES) System for Wind Turbines, in: Volume 2: Diagnostics and Detection; Drilling; Dynamics and Control of Wind Energy Systems; Energy Harvesting; Estimation and Identification; Flexible and Smart Structure Control; Fuels Cells/Energy Storage; Human Robot Interaction; HVAC Building Energy M, Vol. 2, American Society of Mechanical Engineers, 2015, p. T21A005. doi:10.1115/DSCC2015-9957.

[99] M. Saadat, A. Srivatsa, P. Y. Li, T. Simon, Air compression performance improvement via trajectory optimization: Experimental validation, 
$1 \quad$ in: ASME 2016 Dynamic Systems and Control Conference, 2016, pp.

2 V001T04A005-V001T04A005. doi:10.1016/j.dental.2007.04.014.

3 [100] J. H. Wieberdink, Increasing Efficiency and Power Density Of a Liquid

4 Piston Air Compressor / Expander With Porous Media Heat Transfer

5 Elements, Ph.D. thesis, University of Minnesota (2014). arXiv:arXiv:

$6 \quad 1011.1669 v 3$

7 [101] C. Zhang, T. W. Simon, P. Y. Li, J. D. Van De Ven, Numerical modeling of three-dimensional heat transfer and fluid flowthrough interrupted plates using unit cell scale, Special Topics and Reviews in Porous Media 6 (2) (2015) 145-158. doi:10.1615/.2015012321.

[102] A. T. Rice, Heat transfer enhancement in a cylindrical compression chamber by way of porous inserts and the optimization of compression and expansion trajectories for varying heat transfer capabilities., Master's thesis, University of Minnesota (2011).

[103] J. M. Smith, Heat and mass transfer in packed beds, N. Wakao and S. Kaguei, Gordon and Breach Science Publishers, 1983,364 pages, AIChE Journal 29 (6) (1983) 1055-1055. doi:10.1002/aic.690290627.

[104] W. Lu, C. Y. Zhao, S. A. Tassou, Thermal analysis on metal-foam filled heat exchangers. Part I: Metal-foam filled pipes, International Journal of Heat and Mass Transfer 49 (15-16) (2006) 2751-2761. doi:10.1016/j. ijheatmasstransfer.2005.12.012. 